\title{
Analysis of Thermal Error Model of Ball Screw Feed System Based on Experimental Data
}

\author{
Jiancheng Yang \\ Northeastern University \\ Changyou Li ( $\nabla$ chyli@mail.neu.edu.cn ) \\ Northeastern University https://orcid.org/0000-0003-0076-074X \\ Mengtao Xu \\ Northeastern University \\ Yimin Zhang \\ Shenyang University of Chemical Technology
}

\section{Research Article}

Keywords: Temperature, Ball screw feed system, Thermal model, Experimental data, Influence factors

Posted Date: April 19th, 2021

DOI: https://doi.org/10.21203/rs.3.rs-407988/v1

License: (c) (1) This work is licensed under a Creative Commons Attribution 4.0 International License. Read Full License

Version of Record: A version of this preprint was published at The International Journal of Advanced Manufacturing Technology on January 25th, 2022. See the published version at https://doi.org/10.1007/s00170-022-08752-w. 


\section{Analysis of Thermal Error Model of Ball Screw Feed System Based on Experimental Data}

Jiancheng Yang ${ }^{\mathrm{a}},{\text { Changyou } \mathrm{Li}^{\mathrm{a}}{ }^{*} \text {, Mengtao } \mathrm{Xu}^{\mathrm{a}} \text {, Yimin Zhang }}^{\mathrm{b}}$

a School of Mechanical Engineering and Automation, Northeastern University, Shenyang 110819, China

b School of Energy and Power Engineering, Shenyang University of Chemical Technology, Shenyang 110142, China

*Corresponding author.

E-mail address: chyli@mail.neu.edu.cn (C. Li).

\section{Abstract}

In order to investigate the effect of thermal expansion on the ball screw feed system (BSFS) of a precision machine tool, theoretical modeling of and experimental study on thermally induced error are focused in this paper. A series of thermal experiments are conducted on the machine tool to measure the temperature of the main heat source and measuring points of BSFS. To classify the main heat sources and discuss the impact on the ball screw feed system separately. By the experimental data of ball screw system, the thermal model of screw shaft in the axial direction is analyzed and verified. Based on the heat generation and transfer analysis of ball screw system, thermal expansion of screw shaft in the axial direction is modeled mathematically. In addition, by analyzing the effects of machining parameters such as rotational speed, preloads and lead, we get the parameter influence of BSFS's temperature rising and thermal deformation. This work can help us reduce thermal deformation effectively, and improve the precision of CNC machining.

Key words: Temperature; Ball screw feed system; Thermal model; Experimental data; Influence factors.

\section{Introduction}

Machine tools and their components are sensitive to temperature change that could exert an influence on mechanical structure deformation thereby inducing thermal error of motion drive systems [1]. Studies have shown that, for high-speed and high-precision machine tools, processing and manufacturing errors caused by thermal deformation account for about $40 \%$ to $70 \%$ of the total manufacturing errors [2] .Therefore, the research of machine tool thermal error has become an important research direction.

Of all factors that contribute to the thermal error of a machine tool, thermal error of ball screw system plays a very important role [1]. In order to investigate the thermal error of the ball screw, the finite element model are frequently performed [3]. Week $\mathrm{M}$ uses the finite element method-possibilities and limitations to compute the thermal of machine tools [4].Xu et al. [5] used the finite element method to estimate the thermal error of the ball screw system and effectiveness of the air cooling system. $X$ Ming [6] developed an integrated thermal model by the aid of the finite-element method to analyze the temperature distribution of a ball screw feed drive system, considering the thermal contact resistance between the bearing and its housing. Li [7] provides a comprehensive error compensation method for the time-varying positioning error of machine tools based on simulation and experimental analysis. A. Oyanguren [8] presents a numerical modelling strategy to predict the preload variation due to temperature increase using a thermo-mechanical 3D finite element method based model for double nut-ball screw drives. Huang [9] studies further the relationship between thermal deformation and heat quantity through modeling the thermal deformations of stretching bar and bending beam using heat quantity as the 
independent variable, and the stretching model is verified based on finite element method. Zhang [10] develops an adaptive real-time model for predicting the thermal characteristics of the ball screw drive system on line with a finite element method integrated with the Monte Carlo method. Nevertheless, few researchers focused on how to get the analytical solution of the thermal model through theoretical methods.

A good thermal error model with high accuracy and robustness is the key factor for error compensation [11-15]. Lee [16] presents a thermal error model using a fuzzy logic strategy, which does not require any complex procedure such as multiregression or information about the characteristics of the plant. But the error model parameters are only calculated mathematically. Ma [17] proposes the predictive model for thermal contact conductance based on the micro morphology description of rough surfaces and the contact load distribution of solid joints. Then, the dynamic thermal-structure model of the ball screw feed drive system was established. Han [18] presents a new approach for building an effective mathematic thermal error for machine tools which is capable of improving the accuracy of the machine tool effectively. $\mathrm{Wu}$ [19] introduced a comprehensive multiple regression method to study the relationship between temperature variation and thermal error for a ball screw system. Wang [20] proposed a compound error model for the geometric and thermal errors of a milling center based on Newton interpolation. Most of the work done above focused on studying the relationship between thermal error and the temperature of the key heat source. However, under changing thermal conditions, the temperature field of the ball screw is usually inconsistent with the temperature of the key heat source.

There are also some researchers who focus on the measurement of temperature changes during the operation of machine tools. $\mathrm{Wu}$ [21] proposes a thermal error model based on the five key temperature points by using genetic algorithm-based back propagation neural network, which improves the accuracy and reduces computational cost for the prediction of thermal deformation in the turning center. $\mathrm{Xu}$ et al [22, 23] introduced an improved ball screw feed drive thermal error compensation system. Based on this system, the stroke input was calculated and modified by the controller of control unit and then the compensation was completed. Zhang [24] presents different prediction models for positioning error of ball screw feed drive system based on the mounting condition. And the coefficients in the model are identified using the multiple linear regression method. Wei [25] leads to the proposal of a comprehensive temperature-feature extraction method that uses feature extraction algorithm and weight optimization to construct linear temperature-sensitive points. Experimental facilities verified the feasibility of its proposal. Sun [26] presented a precision testing method called seven-sensor configuration method to measure the thermal errors of a horizontal machining center with linear optical grating scale. Li [27] tests the temperatures and positional deviations of the ball screw feed drive system and the linear motor feed drive system equipped with linear scales, and analyzes the factors that affect the positioning error. Then, the temperatures and positioning coordinates were used as inputs to build the thermally induced positional deviation model of full closed-loop feed drive system.

In this paper, based on the thermal boundary obtained from the experiment, we get the analytical solution of the thermal model of the ball screw feed system. Based on the definition of thermal expansion, the axial thermal elongation of the screw is calculated, and the temperature of the screw at different positions is measured experimentally, and the correctness of the model is verified by comparison with theoretical data. Finally, the influence of system parameters on the temperature field 
of the ball screw feed system is discussed.

\section{Thermal error model of BSFS}

\subsection{Heat generation and thermal boundary conditions}

The generation of heat is the root cause of the temperature rise and thermal deformation of the ball screw feed system. When the BSFS produces thermal deformation, thermal errors occur, too. Before discussing the thermal expansion and deformation of the BSFS, it is assumed that the screw is a solid cylindrical rod and the temperature distribution in the radial direction is uniform.

\subsubsection{Main heat source and heat generation}

When the BSFS is in the transmission work, the heat is generated from friction heat, and the friction heat is mainly caused by the friction between the ball and the raceway or groove during the working process of the bearing and nut. Therefore, the main heat sources include the front and rear bearings and nut pairs, and the heat generation principle diagram is shown in Figure 1.

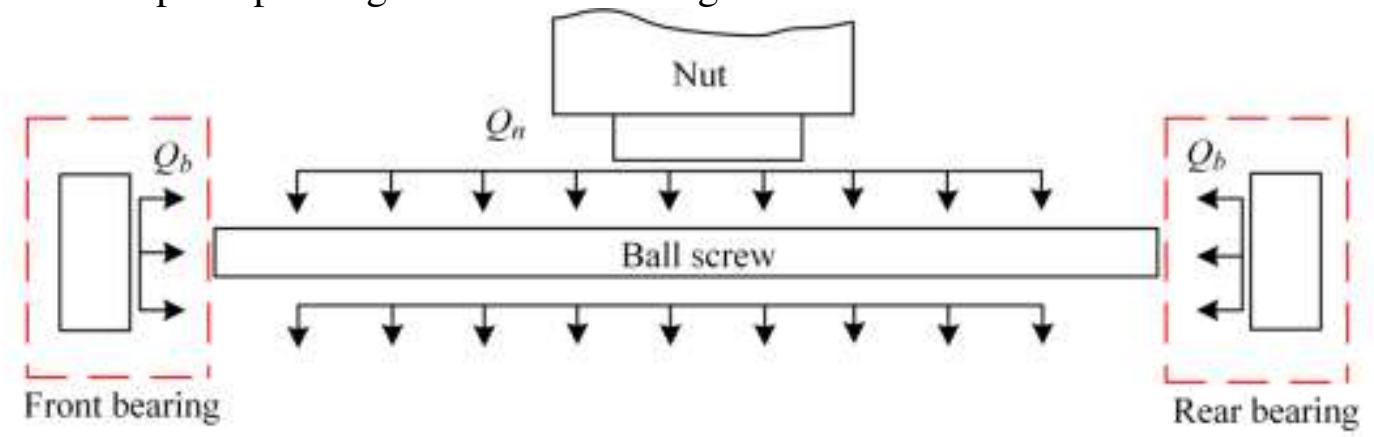

Fig.1 Schematic diagram of heat generation of ball screw feed system

During the working of the ball screw, friction and heat are generated between the bearing balls and the inner and outer rings of the bearing. The friction loss of the bearing is almost entirely converted into heat inside the bearing, which causes the temperature of the bearing to rise. The calorific value of the bearing can be calculated by the following empirical formula [28]:

$$
Q_{b}=1.047 \times 10^{-4} n M_{1}
$$

where $Q_{\mathrm{b}}$ is the calorific value of the bearing; $n$ is the speed of the ball screw; $M_{1}$ is the total friction torque of the bearing.

The preload of the ball screw nut pair will cause friction and heat generation of the nut pair. During the movement of the nut pair on the screw, the ball, the nut and the groove of the screw will rub against each other, producing frictional heat, and the heat will be transferred to the screw. It causes the temperature of the screw to rise. According to the empirical formula, the friction heat of the nut pair can be obtained by the following formula $[29,30]$ :

$$
Q_{n}=0.12 \pi n f_{0} v_{0} M_{2}
$$

where $Q_{\mathrm{n}}$ is the calorific value of the nut; $f_{0}$ is the coefficient related to the nut type and lubrication method; $v_{0}$ is the kinematic viscosity of the lubricating fluid; $M_{2}$ is the total friction torque of the nut.

According to the law of conservation of energy, it can be known that part of the heat generated by the bearing and nut is transferred to the screw, and the other part is lost to the air. The heat lost to the air includes two parts: heat convection heat dissipation and heat radiation heat dissipation. Since the heat radiation loss is relatively small, it can be ignored. Therefore, we have: 


$$
\left\{\begin{array}{l}
Q=Q_{s c}+Q_{s T}+Q_{c} \\
Q_{s c}=c_{s} m_{s}\left(T-T_{0}\right) \\
Q_{s T}=h_{s} A_{s}\left(T-T_{0}\right) \\
Q_{c}=h_{c} A_{c}\left(T_{n}-T_{0}\right)
\end{array}\right.
$$

where $Q$ is the heat generated by the bearing or nut; $Q_{\text {sc }}$ is the heat that causes the temperature of the screw to rise; $Q_{\mathrm{sT}}$ is the heat lost by the heat convection of the screw; $Q_{\mathrm{c}}$ is the heat lost to the air by the nut heat convection. $c_{2}$ is the specific heat capacity of the ball screw; $m_{2}$ is the mass of the ball screw; $h_{\mathrm{c}}$ is the convective heat transfer coefficient of the nut; $A_{\mathrm{c}}$ is the surface area of the nut component; $T_{\mathrm{n}}$ is the temperature function of the nut; $\mathrm{T}_{0}$ is the temperature of the air adjacent to the surface; $A_{\mathrm{s}}$ is the surface area of the screw; $h_{\mathrm{s}}$ is the convective heat transfer coefficient of the screw.

Heat dissipates from the ball screw shaft into the ambient air through forced convective heat transfer. The calculation of the heat transfer coefficient for convection follows a series of steps. First, the mean velocity of the fluid with respect to the solid surface is determined. When the parameter is known, the Reynolds number is determined. For the ball screw shaft rotating at an angular velocity of $\delta$, the Reynolds number is written as:

$$
R_{e}=\frac{\delta d^{2}}{2 v_{l}}
$$

where $v_{l}$ is the kinematic viscosity of the air, and $d$ is the diameter of the screw shaft.

Second, the Nusselt number is determined by

$$
N_{u}=0.133 R_{e}^{2 / 3} P_{r}^{1 / 3}
$$

where the Prandtl number $P_{\mathrm{r}}$ is a material parameter of the fluid and calculated as [31].

$$
P_{r}=\frac{C_{l} u_{l}}{\gamma_{l}}
$$

where $C_{l}$ is the specific heat capacitance of the air, $\mu_{l}$ is the dynamic viscosity of the air, and $\gamma_{l}$ is the thermal conductivity of the ambient air.

Then, the heat transfer coefficient is expressed as

$$
h=\frac{N_{u} \gamma_{l}}{d}
$$

2.2 Heat conduction equation of ball screw

The frictional heat of the bearing and the nut will cause the temperature rise of the screw, as its thermal behavior directly makes a great impact on the positioning error of the feed drive system. In order to obtain the thermal deformation of the ball screw, we established the heat conduction equation of the ball screw as follows [32]:

$$
\frac{\partial^{2} T(x, t)}{\partial x^{2}}=\frac{\rho c}{\lambda} \frac{\partial T(x, t)}{\partial t}
$$

where $\lambda$ is the thermal conductivity, $\rho$ is the density, $c$ is the heat capacity.

At the start time, the initial temperature can be regarded as room temperature $T_{0}$.As for the heat boundary conditions of Eq.(4), there are mainly divided into two types[33].

(i) At both ends of the screw shaft, it is supported by bearings, so the temperature at both ends is equal to the temperature of the bearing. Therefore, we have:

$$
\left.T(x, t)\right|_{x=0, l}=T_{b}
$$


where $T_{\mathrm{b}}$ is the bearing temperature, it can be obtained by polynomial fitting of experimental data.

(ii) Assuming that the heat generated by the nut due to friction is uniformly applied to the screw, the temperature function of the nut can be obtained according to Eq. (3).

As shown in Fig. 1, three typical heat sources are contributing to the ball screw temperature rise. Because Eq. (4) is a linear differential equation, the temperature change of ball screw should be equal to the sum of temperature change responding to every single heat source. So we have:

$$
T(x, t)=\sum_{i=1}^{3} T_{i}(x, t)
$$

\subsubsection{Determination of boundary conditions}

The test was completed on the Yingtai CJK6130 CNC machine tool, as shown in Fig.2. Before the test, the ambient temperature $\mathrm{T}_{0}$ was measured and the measured initial ambient temperature was $17^{\circ} \mathrm{C}$. Then an infrared thermal imager is used to take pictures of the front and rear bearings and nut every 10 minutes during the working process of the machine tool, and the real-time temperature data are obtained as shown in Table 1.

Table.1 Temperature of front and rear bearings and nut at different times

\begin{tabular}{ccccccc}
\hline Time $/ \mathrm{min}$ & $0 \mathrm{~min}$ & $10 \mathrm{~min}$ & $20 \mathrm{~min}$ & $30 \mathrm{~min}$ & $40 \mathrm{~min}$ & $50 \mathrm{~min}$ \\
\hline Front bearing temperature $/{ }^{\circ} \mathrm{C}$ & 17.0 & 21.1 & 22.7 & 24.8 & 25.6 & 25.2 \\
Rear bearing temperature $/{ }^{\circ} \mathrm{C}$ & 17.0 & 20.7 & 22.4 & 24.1 & 26.0 & 26.2 \\
Nut temperature $/{ }^{\circ} \mathrm{C}$ & 17.0 & 22.7 & 28.1 & 29.3 & 30.0 & 29.6 \\
\hline
\end{tabular}

The temperature curve of the bearing can be obtained by polynomial fitting as shown in Figure 3 and Figure 4. The temperature function of the bearing can be obtained as Eq. (7) and Eq. (8).

$$
\begin{aligned}
& T_{b 1}(t)=25.6303-8.506 e^{-0.0718 t} \\
& T_{b 2}(t)=28.4766-11.3821 e^{-0.0338 t}
\end{aligned}
$$

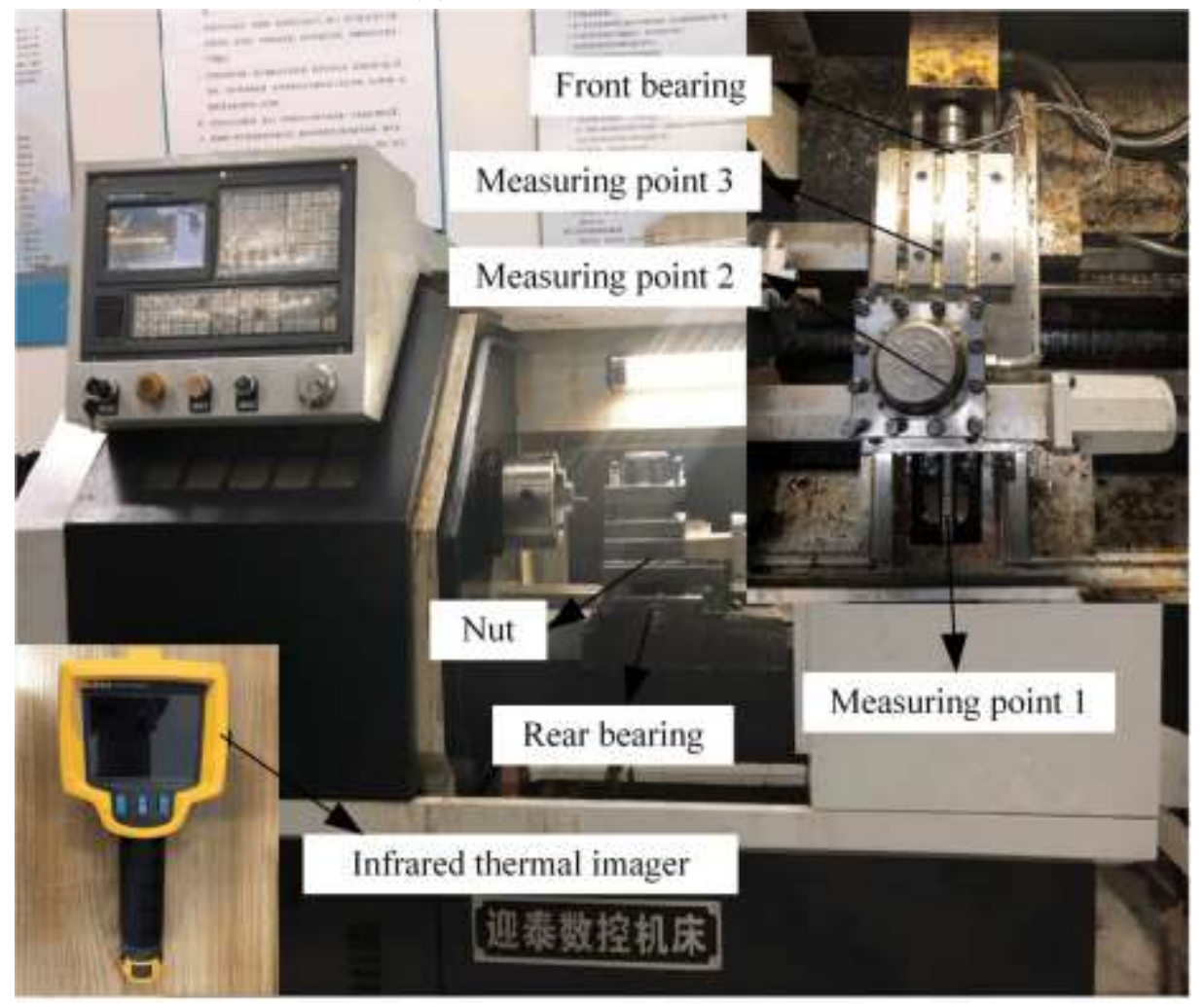


Fig.2.CNC machine tool fittings

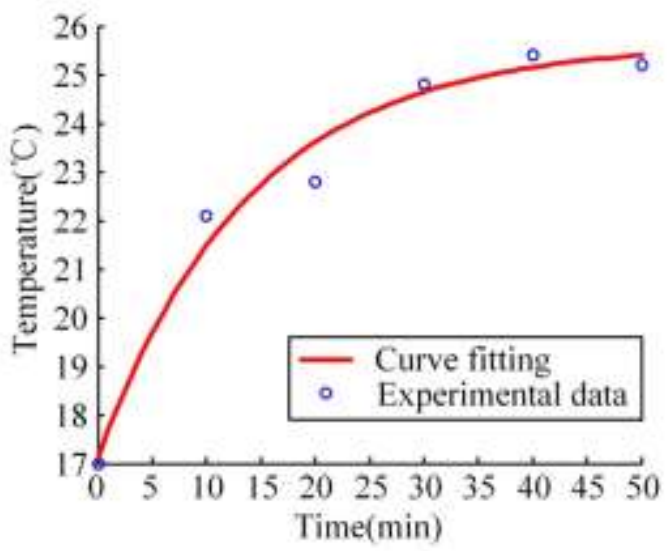

Fig.3. The change curve of the temperature of the front bearing with time

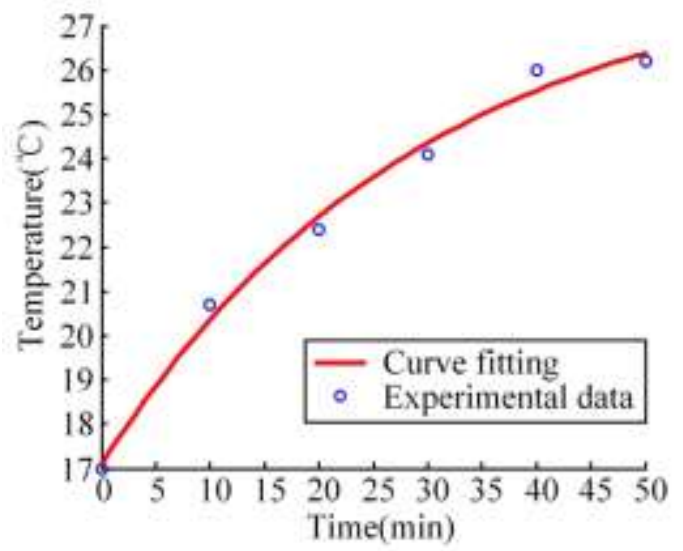

Fig.4. The change curve of the temperature of the rear bearing with time

Similarly, the temperature curve of the nut bearing can be obtained by polynomial fitting, as shown in Figure 5, and the temperature function of the nut can be obtained as Eq. (9).

$$
T_{\mathrm{n}}(t)=30.6726-13.933 e^{-0.0697 t}
$$

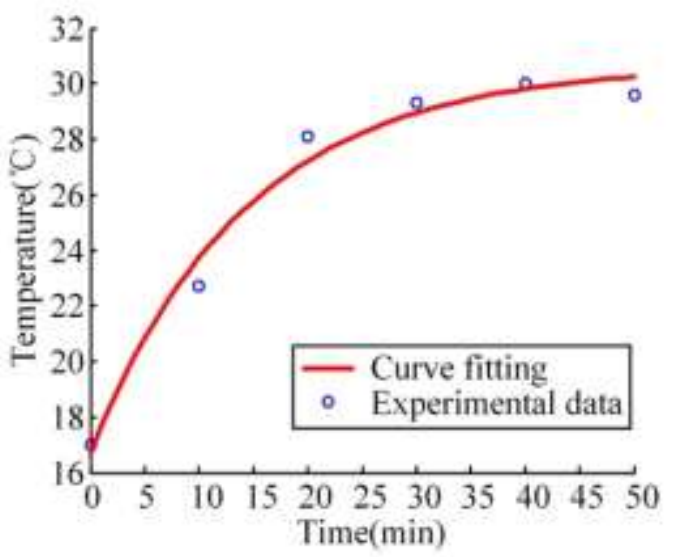

Fig.5. The change curve of the temperature of the nut with time

\subsubsection{Solution of the heat conduction equation}

Based on the experimental data, the temperature function of the boundary conditions is obtained by fitting. But the method of separating variables is only suitable for the case where the differential equations and boundary conditions are both homogeneous, so we need to homogenize the non-homogeneous boundary conditions. The temperature function is expressed as the following form:

$$
T(x, t)=u(x, t)+w(x, t)
$$

where $w(x, t)$ is the selected known function and satisfies the Eq. (7) and Eq. (8). The simplest selection method is the linear function of $x$ as follows:

$$
w(x, t)=A(t) x+B(t)
$$

Substituting the boundary conditions into equation (11), the following equation can be obtained:

$$
\left\{\begin{array}{c}
A(t)=\frac{T_{b 2}(t)-T_{b 1}(t)}{L} \\
B(t)=T_{b 1}(t)
\end{array}\right.
$$


where $\mathrm{L}$ is the length of the ball screw.

Substituting the Eq.(12) into the Eq.(11), So the $w(x, t)$ can be expressed as:

$$
w(x, t)=\frac{T_{b 2}(t)-T_{b 1}(t)}{L} x+T_{b 1}(t)
$$

Substituting Eq. (10) and Eq. (11) into Eq. (4), the following equation can be obtained:

$$
\frac{\partial^{2} u(x, t)}{\partial x^{2}}-\frac{\partial u(x, t)}{\partial t}=\frac{\rho c}{\lambda} \frac{\partial w(x, t)}{\partial t}
$$

As for Eq. (14), it is a non-homogeneous differential equation under homogeneous boundary conditions. So we need to solve the homogeneous analytical solution of the equation. We solve the homogeneous analytical solution of Eq. (15), and the Eq. (15) can be obtained as follows:

$$
u(x, t)=u_{1}(x, t)+u_{2}(x, t)
$$

where $u_{1}(x, t)$ is the solutions of homogeneous partial differential equations under homogeneous boundary conditions. $u_{2}(x, t)$ is the solutions of non-homogeneous partial differential equations under homogeneous boundary conditions.

$$
\begin{gathered}
\left\{\begin{array}{c}
\frac{\partial^{2} u_{1}(x, t)}{\partial x^{2}}-\frac{\partial u_{1}(x, t)}{\partial t}=0 \\
u_{1}(0, t)=0 \\
u_{1}(L, t)=0
\end{array}\right. \\
\left\{\begin{aligned}
& u_{1}(x, 0)=T_{0}-w(x, 0) \\
& \frac{\partial^{2} u_{2}(x, t)}{\partial x^{2}}-\frac{\partial u_{2}(x, t)}{\partial t}=\frac{\rho c}{\lambda} \frac{\partial w(x, t)}{\partial t} \\
& u_{2}(0, t)=0 \\
& u_{2}(L, t)=0 \\
& u_{2}(x, 0)=0
\end{aligned}\right.
\end{gathered}
$$

First, we solve the relatively simple homogeneous partial differential equations. Suppose $u_{1}(x, t)=Y_{1}(x) F_{1}(t)$, then Eq. (16) can be expressed by the method of separating variables as follows [34]:

$$
\frac{1}{Y_{1}(x)} \cdot \frac{d^{2} Y_{1}(x)}{d x^{2}}=a \frac{1}{F_{1}(t)} \cdot \frac{d F_{1}(t)}{d t}
$$

where a represents $\rho c / \lambda$.

If the above equation is true, then both sides must be equal to the same constant $\left(-\omega^{2}\right)$, then the following equation can be obtained:

$$
\frac{1}{Y_{1}(x)} \cdot \frac{d^{2} Y_{1}(x)}{d x^{2}}=a \frac{1}{F_{1}(t)} \cdot \frac{d F_{1}(t)}{d t}=-\omega^{2}
$$

Therefore, we can get two differential equations from Eq. (19) as follows:

$$
\left\{\begin{array}{l}
\frac{d^{2} Y_{1}(x)}{d x^{2}}+\omega^{2} Y_{1}(x)=0 \\
a \frac{d F_{1}(t)}{d t}+\omega^{2} F_{1}(t)=0
\end{array}\right.
$$

Solving the two differential equations in Eq.(20), and then the solution result can be obtained: 


$$
\left\{\begin{array}{c}
Y_{r}(x)=\sin \frac{r \pi}{L} x, r=1,2,3 \ldots \\
F_{1}(t)=C e^{-\frac{1}{a}\left(\frac{\pi r}{L}\right)^{2} t}
\end{array}\right.
$$

Where $C$ is the integral constant, which can be obtained by the boundary conditions.

Therefore substituting the Eq.(21) into $u_{1}(x, t)=Y_{1}(x) F_{1}(t)$, So the solution of $u_{1}$ $(x, t)$ can be expressed as:

$$
u_{1}(x, t)=\sum_{r=1}^{\infty} C e^{-\frac{\omega^{2} t}{a}} \sin \frac{r \pi}{L} x, r=1,2,3 \ldots
$$

Then we solve the non-homogeneous partial equations under the homogeneous boundary by Fourier series expansion method [35]. Taking the solution of Eq.(16) as the eigenfunction which is $\sin (\pi r x / L)$, so the Fourier series of the result and the inhomogeneous term at the right end are expanded as follows:

$$
\begin{gathered}
u_{2}(x, t)=\sum_{r=1}^{\infty} q_{r}(t) \sin \frac{\pi r}{L} x \\
f(x, t)=\sum_{r=1}^{\infty} f_{r}(t) \sin \frac{\pi r}{L} x \\
f_{r}(t)=\frac{2}{L} \int_{0}^{L} f(x, t) \sin \frac{\pi r}{L} x d x, r=1,2,3 \ldots
\end{gathered}
$$

Then substituting equations (23) and (24) into equation (17), the following equation can be obtained:

$$
\sum_{r=1}^{\infty}\left[-\left(\frac{\pi r}{L}\right)^{2} q_{r}(t) \sin \frac{\pi r}{L} x\right]-\sum_{r=1}^{\infty} a q_{r}^{\prime}(t) \sin \frac{\pi r}{L} x=\sum_{r=1}^{\infty} f_{n}(t) \sin \frac{\pi r}{L} x
$$

By simplifying the Eq. (25), the following formula can be obtained:

$$
q_{r}^{\prime}(t)+\frac{\pi^{2} r^{2}}{a L^{2}} q_{r}(t)-\frac{f_{r}(t)}{a}=0, \quad r=1,2,3 \ldots
$$

First, by solving the homogeneous solution of the differential equation corresponding to Eq. (26), and the Eq. (27) can be obtained as follows:

$$
q_{r}(t)=C_{1} \cdot e^{-\frac{\pi^{2} r^{2}}{a L^{2}} t}
$$

Then we use the constant variation method to solve the special solution of Eq.(26).Supposed $C_{1}=h(t)$, the Eq.(27) can be expressed as follows:

$$
q_{r}(t)=h(t) \cdot e^{-\frac{\pi^{2} r^{2}}{a L^{2}} t}, \quad r=1,2,3 \ldots
$$

Substituting Eq.(28) and its derivative result into Eq. (28), the following formula can be obtained:

$$
h^{\prime}(t) \cdot e^{-\frac{\pi^{2} r^{2}}{a L^{2}} t}-h(t) \cdot \frac{\pi^{2} r^{2}}{a L^{2}} e^{-\frac{\pi^{2} r^{2}}{a L^{2}} t}+h(t) \frac{\pi^{2} r^{2}}{a L^{2}} e^{-\frac{\pi^{2} r^{2}}{a L^{2}} t}-\frac{f_{r}(t)}{a}=0, \quad r=1,2,3 \ldots
$$

The solution results of $h(t)$ are as follows:

$$
h(t)=\int \frac{f_{r}(t)}{a} e^{\frac{\pi^{2} r^{2}}{a L^{2}} t} d t, \quad r=1,2,3 \ldots
$$

So the solution of $q_{\mathrm{r}}(t)$ can be obtained as follows: 


$$
q_{r}(t)=\left(\int \frac{f_{r}(t)}{a} e^{\frac{\pi^{2} r^{2}}{a L^{2}}} d t\right) \cdot e^{-\frac{\pi^{2} r^{2}}{a L^{2}}}, \quad r=1,2,3 \ldots
$$

So the solution of the $u_{2}(x, t)$ can be obtained as follows:

$$
u_{2}(x, t)=\sum_{r=1}^{\infty}\left(\int \frac{f_{r}(t)}{a} e^{\frac{\pi^{2} r^{2}}{a L^{2}}} d t\right) \cdot e^{-\frac{\pi^{2} r^{2}}{a L^{2}}} \cdot \sin \frac{\pi r x}{L}
$$

Substituting the Eq. (13), Eq. (22) and Eq. (32) into Eq. (10), under considering the influence of bearing heat source, the temperature rise of the lead screw can be obtained:

$$
T(x, t)=\left[\frac{T_{b 2}(t)-T_{b 1}(t)}{L} x+T_{b 1}(t)\right]+\sum_{r=1}^{\infty}\left(C+\int \frac{\lambda f_{r}(t)}{\rho c} e^{\frac{\lambda \pi^{2} r^{2}}{\rho c L^{2} t}} d t\right) \cdot e^{-\frac{\lambda \pi^{2} r^{2}}{\rho c} L^{2} t} \cdot \sin \frac{r \pi x}{L}
$$

Then, considering the influence of the uniform thermal boundary of the nut on the temperature rise of the screw, the Eq. (9) is substituted into the Eq. (3), and through the law of conservation of energy, Eq.(34) can be obtained as follows:

$$
\frac{0.12 \pi n L_{b}\left[F_{a}\left(1-\eta^{2}\right)+F_{p}(1-\eta)\right] t}{2 \pi \eta}=\left(c_{2} m_{2}+h_{s} A_{s} t\right)\left(T-T_{0}\right)+h_{c} A_{c}\left(T_{n u t}-T_{0}\right) t
$$

After simplifying and separating Eq.(34), the temperature rise of the screw can be obtained:

$$
\Delta T=\frac{0.12 \pi n L_{b}\left[F_{a}\left(1-\eta^{2}\right)+F_{p}(1-\eta)\right] \times t / 2 \pi \eta-h_{c} A_{c}\left(T_{n u t}-T_{0}\right) t}{c_{2} m_{2}+h_{s} A_{s} t}
$$

Where $c_{2}$ is the specific heat capacity of the ball screw; $m_{2}$ is the mass of the ball screw; $h_{\mathrm{c}}$ [36] is the convective heat transfer coefficient of the nut; $A_{\mathrm{c}}$ is the surface area of the nut assembly; $F_{\mathrm{p}}$ is the preload of the nut pair of the ball screw; $L_{\mathrm{b}}$ is the lead of the screw; $\eta$ is The efficiency of the ball screw pair; $F_{a}$ is the axial load; $A_{\mathrm{s}}$ is the surface area of the screw; $h_{\mathrm{s}}$ is the convective heat transfer coefficient of the screw.

$$
\begin{aligned}
& T(x, t)=\left[\frac{T_{b 2}(t)-T_{b 1}(t)}{L} x+T_{b 1}(t)\right]+\sum_{r=1}^{\infty}\left(C+\int \frac{\lambda f_{r}(t)}{\rho c} e^{\frac{\lambda \pi^{2} r^{2}}{L^{2}} t} d t\right) \cdot e^{-\frac{\lambda \pi^{2} r^{2}}{\rho c} L^{2}} \cdot \sin \frac{r \pi x}{L} \\
& +\frac{0.12 \pi n L_{b}\left[F_{a}\left(1-\eta^{2}\right)+F_{p}(1-\eta)\right] \times t / 2 \pi \eta-h_{c} A_{c}\left(T_{n u t}-T_{0}\right) t}{c_{2} m_{2}+h_{s} A_{s} t}
\end{aligned}
$$




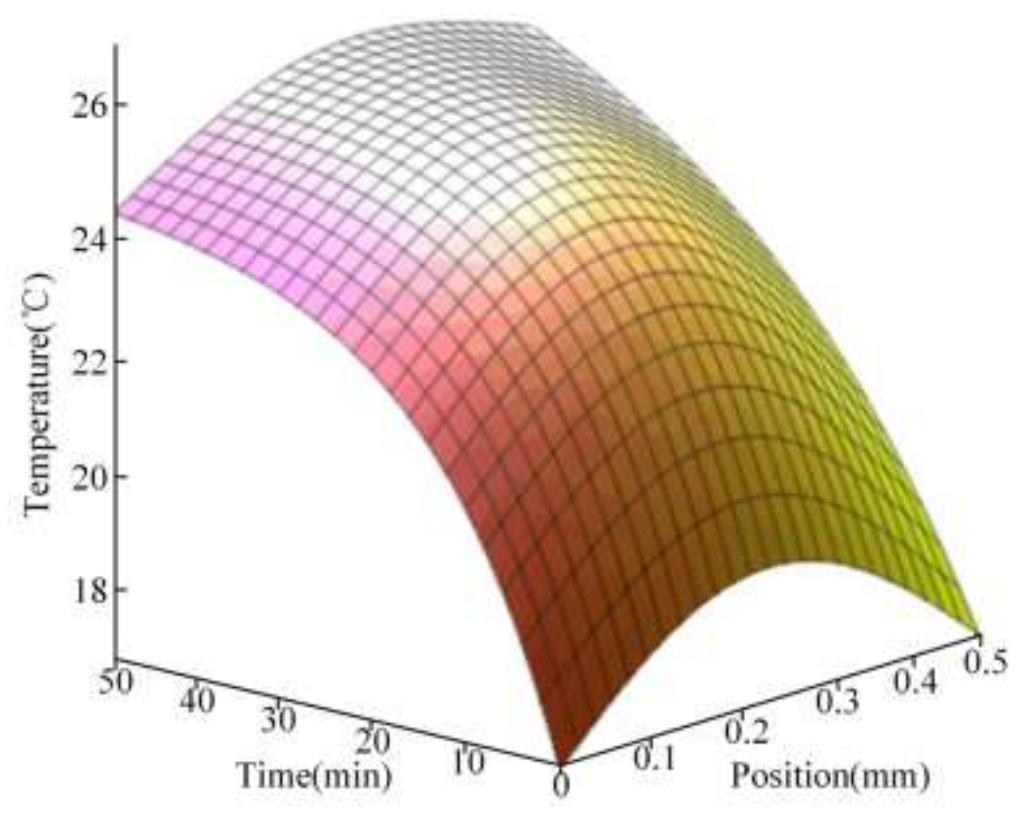

Fig.6. The change curve of the temperature of the ball screw with time and position

In summary, the temperature rise of the lead screw caused by the two types of heat sources is added together, and the temperature of the lead screw can be expressed as Eq.(36),and the change curve of the temperature of the ball screw with time and position is shown as Fig.6.

2.3 Thermal deformation analysis

From a macro perspective, the thermal effect of the screw shaft of the ball screw feed system is axial elongation. For the screw shaft, the principle can be shown in Figure 7.

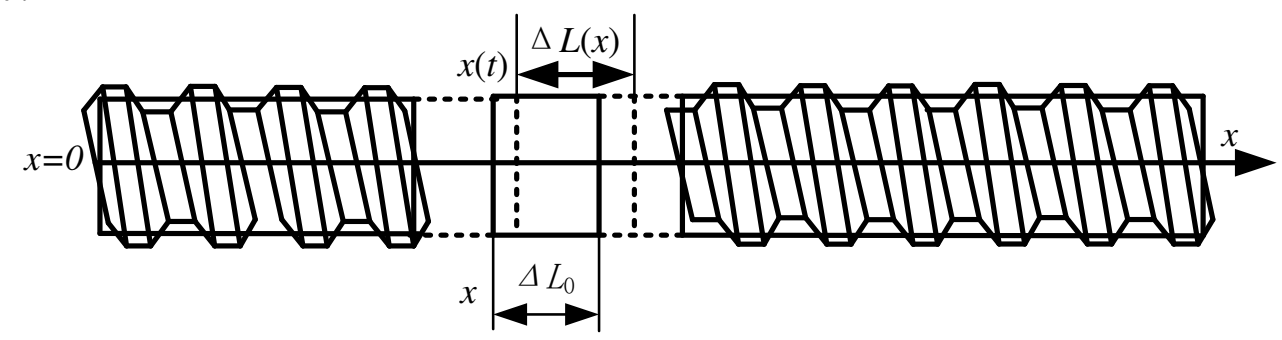

Fig.7 Schematic diagram of thermal expansion analysis of ball screw

Consider a very small part of $\Delta L_{0}$ for analysis ( $\Delta L_{0}$ is small enough). At time $t$, the temperature increases from $T_{0}$ to $T(x, t)$, the length extends to $\Delta L(x)$, and the point $x$ moves to $x(\mathrm{t})$. The axial deformation at position $x$ can be obtained by Eq. (37) [37].

$$
x(t)-x=\int_{0}^{x} \alpha\left(T(x, t)-T_{0}\right) d \delta
$$

Where $\alpha$ is the thermal expansion coefficient.

So the thermal expansion deformation of a ball screw with a length of $L$ can be expressed as:

$$
\Delta L=L(t)-L=\int_{0}^{L} \alpha\left(T(x, t)-T_{0}\right) d x
$$

Substituting Eq. (36) into Eq. (38), the following equation can be obtained: 


$$
\Delta L=\int_{0}^{L} \alpha\left(\begin{array}{l}
{\left[\frac{T_{b 2}(t)-T_{b 1}(t)}{L} x+T_{b 1}(t)\right]+\sum_{r=1}^{\infty}\left(C+\int \frac{\lambda f_{r}(t)}{\rho c} e^{\frac{\lambda \pi^{2} r^{2}}{\rho c} L^{2}} d t\right) \cdot e^{-\frac{\lambda \pi^{2} r^{2}}{\rho c} L^{L^{2}}} \cdot \sin \frac{r \pi x}{L}} \\
+\frac{0.12 \pi n L_{b}\left[F_{a}\left(1-\eta^{2}\right)+F_{p}(1-\eta)\right] \times t / 2 \pi \eta-h_{c} A_{c}\left(T_{n u t}-T_{0}\right) t}{c_{2} m_{2}+h_{s} A_{s} t}-T_{0}
\end{array}\right) d x
$$

\section{Experimental verification of BSFS thermal error model}

In the previous section, the temperature field model of the ball screw feed system has been established and solved analytically, and the temperature of the ball screw is obtained as a function of time and position. In order to verify the correctness of the model and the solution results, experiments are required verification. The correctness of the solution is verified by comparing the experimentally measured data with the theoretically calculated temperature. First, before the machine tool is started, measure the room temperature and record the initial temperature, and then select 3 points at $100 \mathrm{~mm}, 200 \mathrm{~mm}$ and $400 \mathrm{~mm}$ on the lead screw as the test objects as shown in Fig.2 and Fig.7. Using an infrared thermal imager to measure the temperature of selected some points on the ball screw every 10 minutes and record it in Table 1.

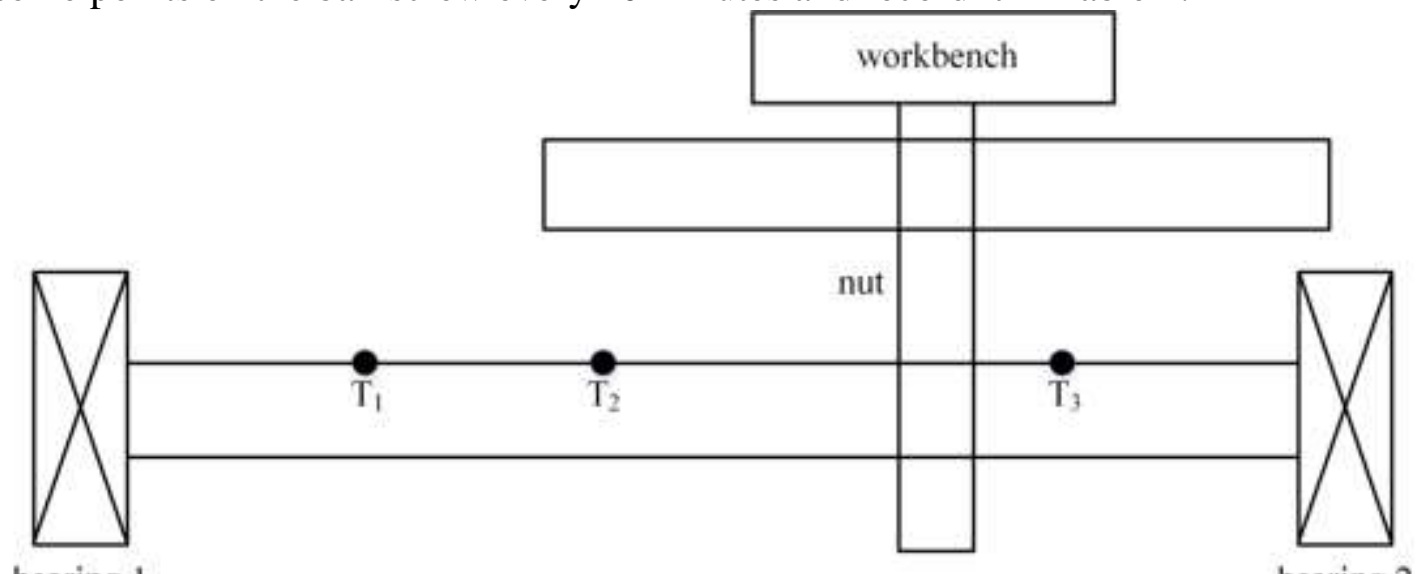

bearing 1

bearing 2

Fig.8. Distribution of measured points for the screw Table. 1 The temperature of the screw shaft at different positions

\begin{tabular}{rcccccc}
\hline Time $/$ min & Omin & $10 \min$ & $20 \min$ & $30, \min$ & $40 \mathrm{~min}$ & $50 \min$ \\
\hline $100 \mathrm{~mm} /{ }^{\circ} \mathrm{C}$ & 17.0 & 19.9 & 21.1 & 22.7 & 23.7 & 23.6 \\
$200 \mathrm{~mm} /{ }^{\circ} \mathrm{C}$ & 17.0 & 19.7 & 23.2 & 24.6 & 24.7 & 24.9 \\
$400 \mathrm{~mm} /{ }^{\circ} \mathrm{C}$ & 17.0 & 19.5 & 20.9 & 21.5 & 22.1 & 22.3 \\
\hline
\end{tabular}




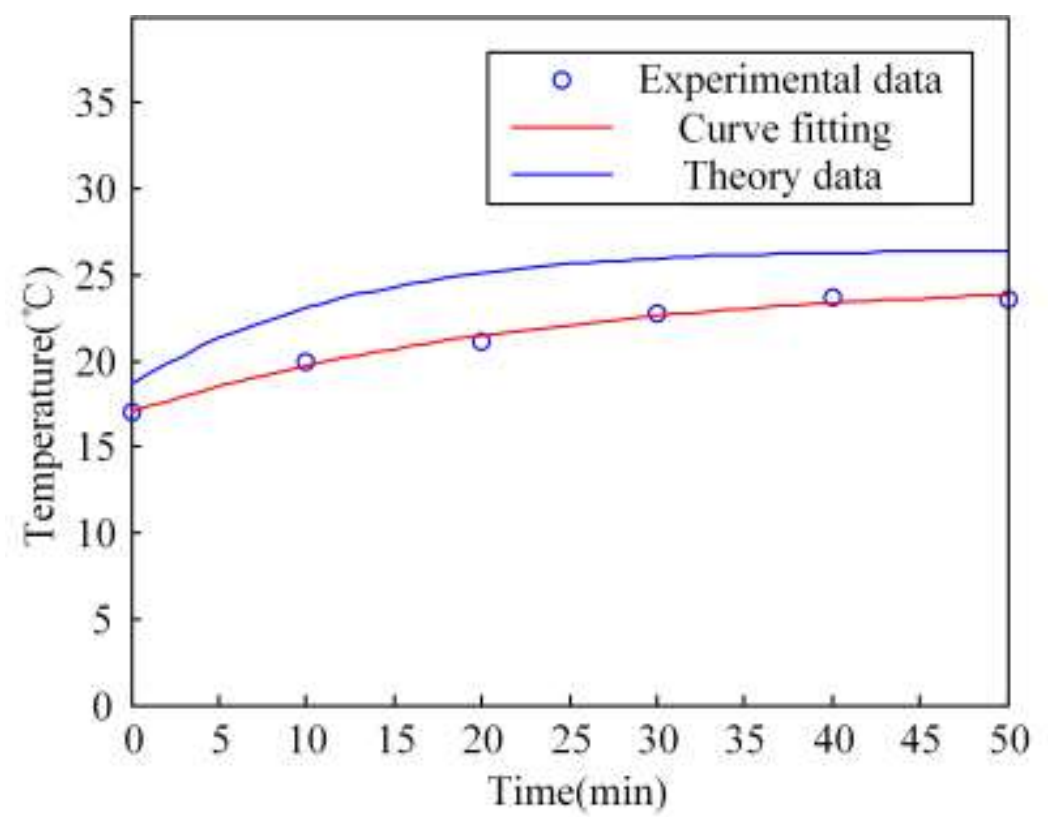

Fig.9 Comparison of test and theoretical temperature of ball screw at $100 \mathrm{~mm}$

Figure 9 shows the test measurement data at the $100 \mathrm{~mm}$ position of the ball screw and the theoretical simulation temperature versus time curve. Through calculation, it can be seen that the relative error between the test and the theoretical temperature is $10.38 \%$, which is within the allowable tolerance within range.

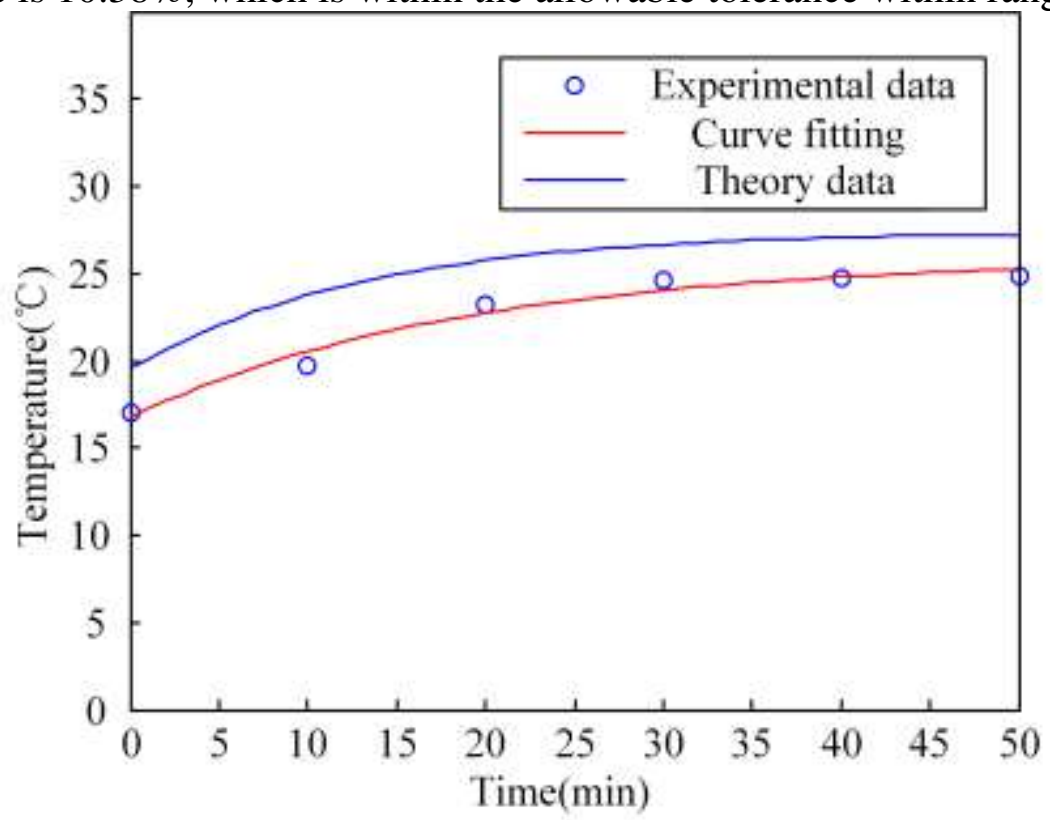

Fig.10 Comparison of test and theoretical temperature of ball screw at $200 \mathrm{~mm}$

Figure 10 shows the experimental measurement data at the $200 \mathrm{~mm}$ position of the ball screw and the theoretical simulation temperature variation curve with time. Through calculation, it can be seen that the relative error between the experimental and theoretical temperature is $9.58 \%$, which is within the allowable tolerance within range. 


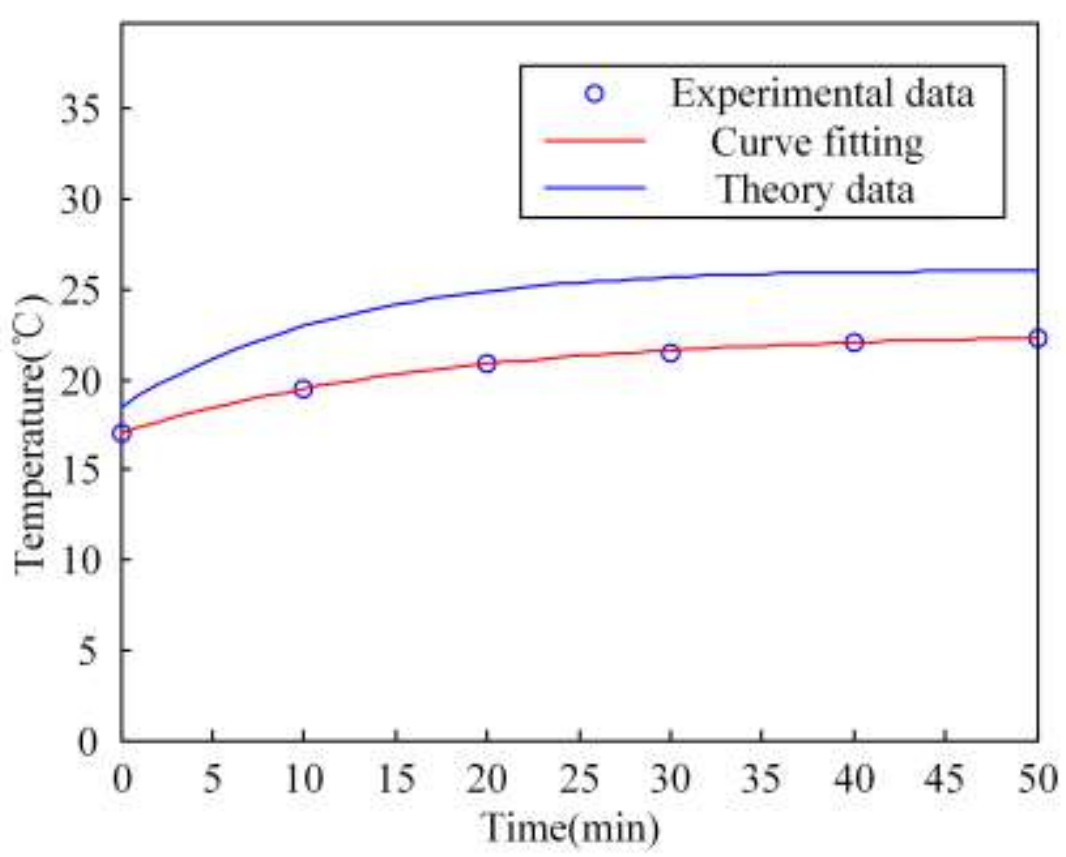

Fig.11 Comparison of test and theoretical temperature of ball screw at $400 \mathrm{~mm}$

Figure 11 shows the experimental measurement data at the $400 \mathrm{~mm}$ position of the ball screw and the theoretical simulation temperature change curve. Through calculation, it can be seen that the relative error between the experimental and theoretical temperature is $12.2 \%$, which is within the allowable error within range.

In summary, the relative errors between the experimental data and theoretical simulation data at three locations at $100 \mathrm{~mm}, 200 \mathrm{~mm}$, and $400 \mathrm{~mm}$ that we selected are all less than $15 \%$, which is within the allowable range of error, verifying the theoretical model and solution results.

\section{Influencing factors of BSFS}

In this section, the nut is taken as the research object, and its influence on the temperature field change and thermal deformation of the system is studied by changing some basic parameters [38]. It can be found from Eq.(19) that the parameters that affect the temperature rise of the system include speed, initial preload, lead, and axial load.

4.1 The influence of rotational speed

As shown in Figure 10, the temperature rise of the ball screw varies with the speed. Here, three different speeds of $1000 \mathrm{r} / \mathrm{min}, 2000 \mathrm{r} / \mathrm{min}$ and $3000 \mathrm{r} / \mathrm{min}$ are selected to study the speed of the ball screw feed system and its temperature Impact of the field. It can be seen that as the rotation speed increases, the temperature of the ball screw gradually increases. It can also be found that the faster the rotation speed, the shorter the time to reach thermal equilibrium. Therefore, when the machine is preheated, a higher speed is used for preheating, and the thermal equilibrium is reached faster to improve the processing accuracy. 

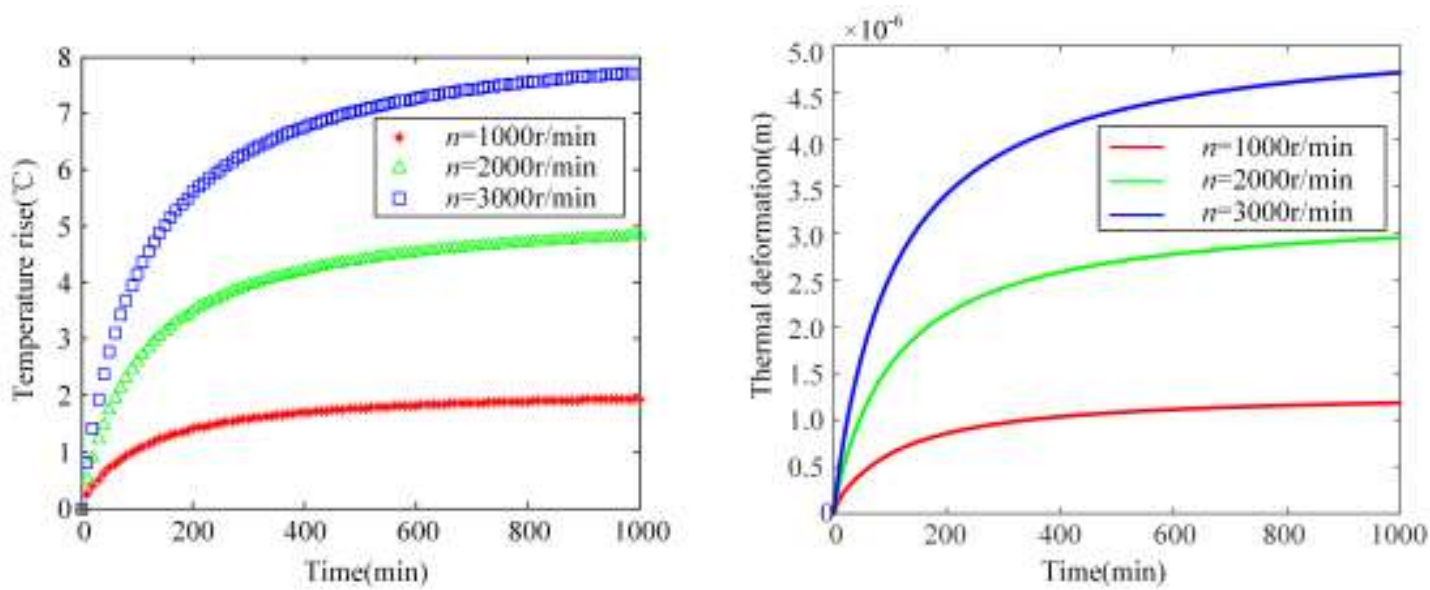

Fig.12 The temperature rising and thermal deformation of the lead screw changes with the speed

In Figure 12, the maximum temperature rise of the lead screw during thermal equilibrium can be obtained. According to the thermal deformation Eq.(22), the thermal deformation of the lead screw can be calculated as shown in Table 2 . It can be found that as the temperature increases, the thermal deformation gradually becomes larger.

Table.2 Temperature rise and thermal deformation of the system at different speeds

\begin{tabular}{ccc}
\hline Rotating speed $(\mathrm{r} / \mathrm{min})$ & Temperature rise $\left({ }^{\circ} \mathrm{C}\right)$ & Thermal deformation $(\mathrm{mm})$ \\
\hline 1000 & 2.1 & 0.001178 \\
2000 & 5.0 & 0.002939 \\
3000 & 8.2 & 0.004698 \\
\hline
\end{tabular}

\subsection{The influence of preload}

As figure 13 shows the curve of the temperature rise of the ball screw with the initial preload. Three different initial preloads of $1000 \mathrm{~N}, 2000 \mathrm{~N}$ and $3000 \mathrm{~N}$ are selected to study the preload of the ball screw feed system. The influence of its temperature field. It can be seen that as the pre-tightening force increases, the temperature of the ball screw gradually increases.

Table.3 Temperature rise and thermal deformation of the system at different preload

\begin{tabular}{ccc}
\hline Preload $(\mathrm{N})$ & Temperature rise $\left({ }^{\circ} \mathrm{C}\right)$ & Thermal deformation $(\mathrm{m})$ \\
\hline 1000 & 3.3 & 0.001871 \\
1500 & 4.7 & 0.002646 \\
2000 & 5.9 & 0.003418 \\
\hline
\end{tabular}

As Table. 3 shown is the maximum temperature and the thermal deformation of different preload. It can be found that as the temperature increases, the thermal deformation gradually becomes larger. The influence of preload on the temperature rise and thermal deformation of the screw is greater than the influence of the speed.
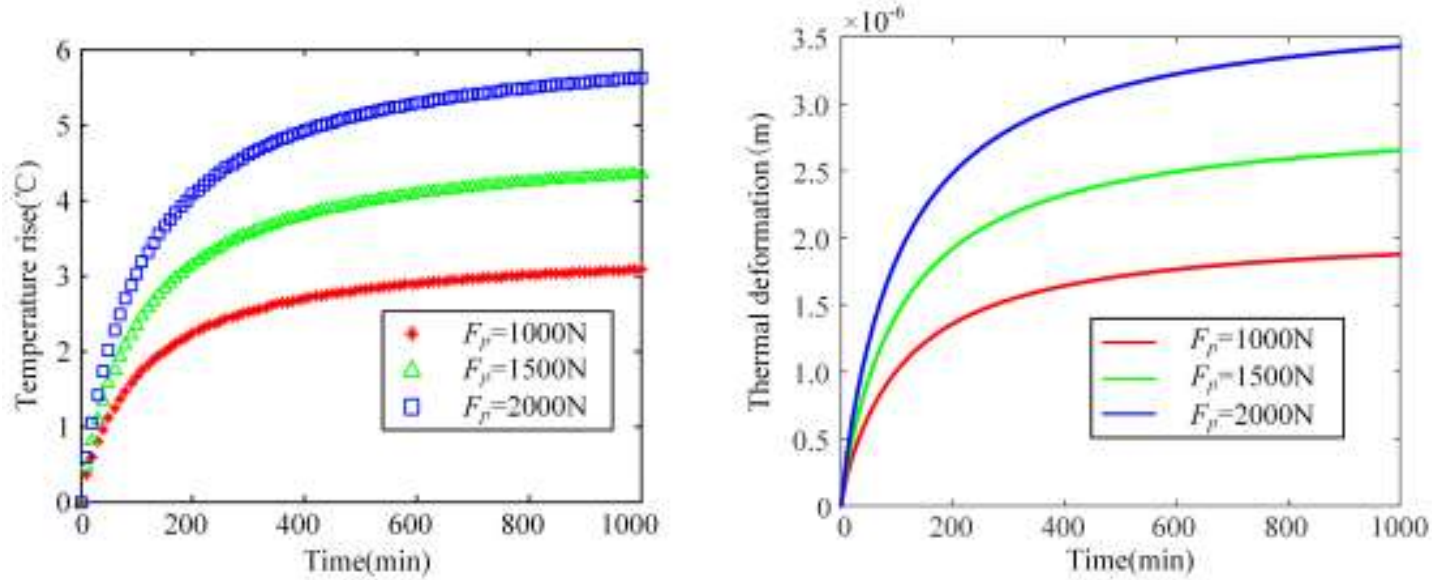
Fig.13 The temperature rising and thermal deformation of the lead screw changes with the preload 4.3 The influence of lead

As Figure.14 shown the lead of BSFS affects the temperature variation of the nut. Three different lead of $10 \mathrm{~mm}, 12 \mathrm{~mm}$ and $15 \mathrm{~mm}$ are selected to study the lead of the ball screw feed system. As the lead of the screw increases, the temperature of the ball screw increases in general.

Table.4 Temperature rise and thermal deformation of the system at different preload

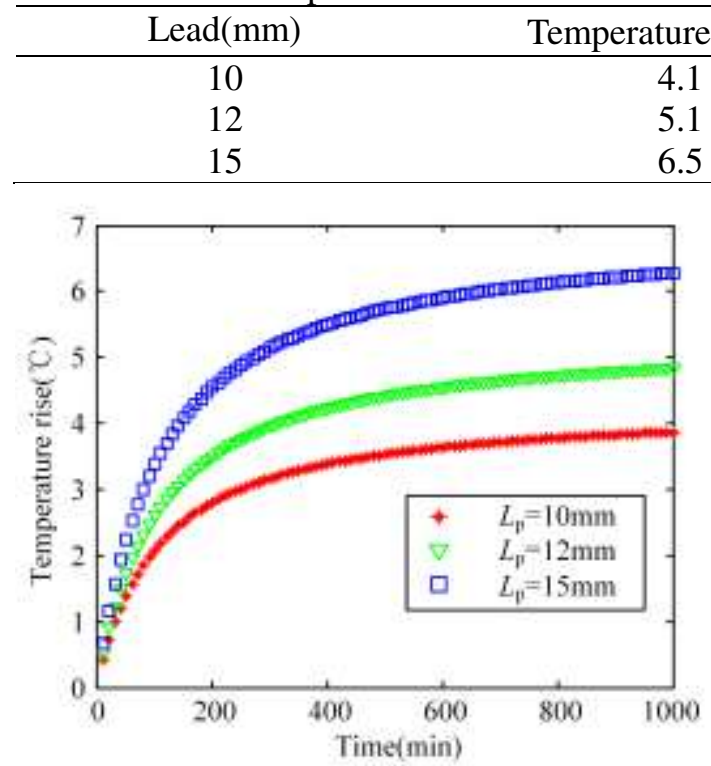

$\begin{array}{ll}4.1 & 0.002147 \\ 5.1 & 0.002682 \\ 6.5 & 0.003485\end{array}$

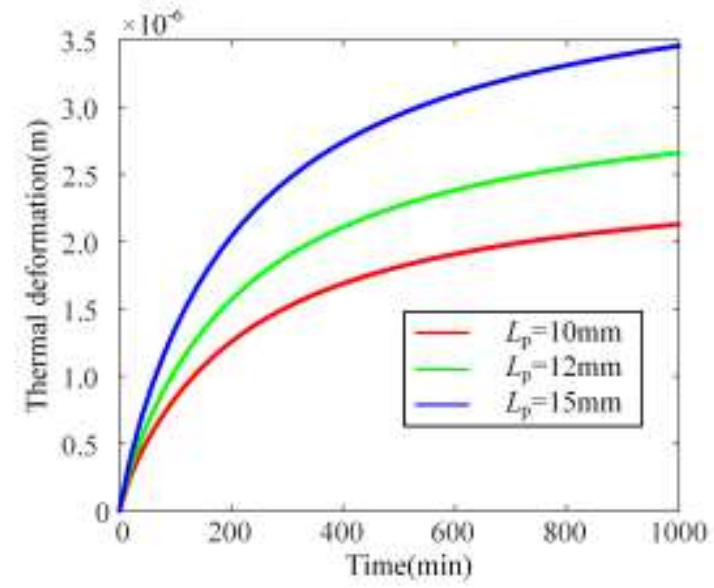

Fig.14. The temperature rising and thermal deformation of the lead screw changes with the lead

As Table. 4 shown is the maximum temperature and thermal deformation of different lead. It can be found that as the temperature increases, the thermal deformation gradually becomes larger. There is an approximately linear increase between the change in temperature rise and thermal deformation and the lead.

4.4 The influence of Convection heat transfer coefficient

As Figure.15 shown the convection heat transfer coefficient of ball screw affects the temperature variation of the nut. Three different convection heat transfer coefficient of $100 \mathrm{~W} /\left(\mathrm{m}^{2 .}{ }^{\circ} \mathrm{C}\right), 250 \mathrm{~W} /\left(\mathrm{m}^{2 .}{ }^{\circ} \mathrm{C}\right)$ and $400 \mathrm{~W} /\left(\mathrm{m}^{2 .}{ }^{\circ} \mathrm{C}\right)$ are selected to study the convection heat transfer coefficient of the ball screw feed system. As the convection heat transfer coefficient of the screw increases, the temperature of the ball screw reduces in general.
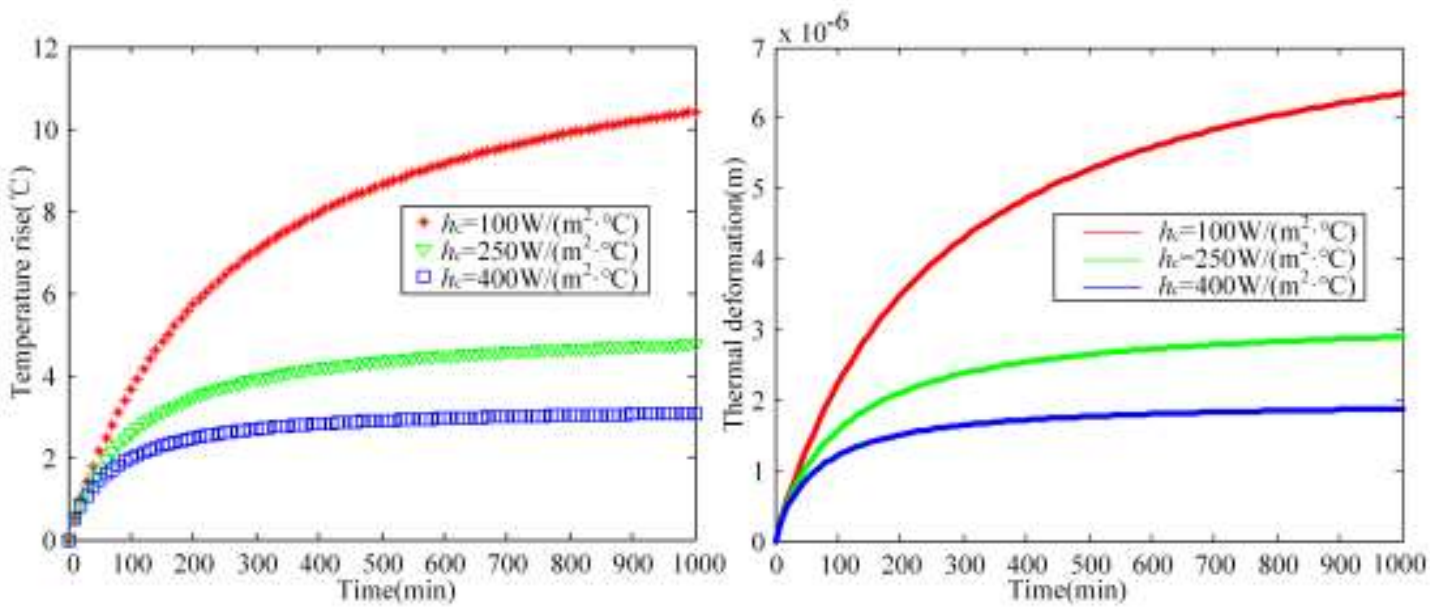

Fig.14. The temperature rising and thermal deformation of the lead screw changes with the lead

As Table.5 shown is the maximum temperature and thermal deformation of different convection heat transfer coefficient. It can be found that as the temperature 
increases, the thermal deformation gradually becomes smaller. There is an approximately linear reduce between the change in temperature rise and thermal deformation and the lead. Therefore, in order to reduce the influence of thermal deformation, the convection heat transfer coefficient should be increased as much as possible.

Table.5 Temperature rise and thermal deformation of the system at different Convection heat transfer coefficient

\begin{tabular}{ccc}
\hline$h_{\mathrm{c}}\left(\mathrm{W} /\left(\mathrm{m}^{\left.\left.2 \cdot{ }^{\circ} \mathrm{C}\right)\right)}\right.\right.$ & Temperature rise $\left({ }^{\circ} \mathrm{C}\right)$ & Thermal deformation $(\mathrm{mm})$ \\
\hline 100 & 10.4 & 0.006349 \\
250 & 4.7 & 0.002890 \\
400 & 3.1 & 0.001873 \\
\hline
\end{tabular}

\section{Conclusion}

This paper solves the thermal error model of the ball screw by using the Fourier series expansion method, and investigates the relationship between the temperature rise and thermal deformation of the ball screw. We got the temperature field model of the BSFS. Based on the results and analysis, some conclusions can be drawn as follows: (1) As time increases, the temperature of the lead screw gradually rises and finally reaches a thermal equilibrium state; as the length of the lead screw increases, the thermal elongation of the axis will increase.

(2) As the speed, preload and lead increase, the temperature and thermal deformation of the ball screw gradually increase. The influence of preload on the temperature rising and thermal deformation of the screw is greater than the influence of the speed on it.

\section{Declarations}

\section{Funding}

The work was supported by National Natural Science Foundation of China (Grant No. 52075087), the Fundamental Research Funds for the Central Universities (Grant No. N2003006 and N2103003), National Natural Science Foundation of China (Grant No. U1708254)

\section{Conflicts of interest}

The authors declare that they have no known competing financial interests or personal relationships that could have appeared to influence the work reported in this paper.

\section{Availability of data and material}

The data sets supporting the results of this article are included within the article and its additional files.

\section{Authors' contributions}

Jiancheng Yang: Methodology; Investigation; Experimental; Writing-Original Draft; Writing- Review \& Editing

Changyou Li: Resources and Supervision,

Mengtao Xu: Resources, Writing- reviewing and editing, Supervision, WritingReview \& Editing

Yimin Zhang: Resources and Supervision

\section{Ethics approval}

This chapter does not contain any studies with human participants or animals performed by any of the authors.

\section{Consent to participate}

Not applicable. The article involves no studies on humans.

\section{Consent for publication}

All authors have read and agreed to the published version of the manuscript. 


\section{References}

[1] Hu S, Ma C, Y J, Zhao L, Mei X, Gong G, Investigation into effect of thermal expansion on thermally induced error of ball screw feed drive system of precision machine tools. Int J Mach Tools Manuf 97(2015)60-17.

[2]Mayr J, Jedrzejewski J, Uhlmann E, et al., Thermal issues in machine tools, CIRP Ann. - Manuf. Technol. 61 (2) (2012) 771-791.

[3]Venugopal R, Barash M, Thermal effects on the accuracy of numerically controlled machine tools. CRIP Ann Manuf Techn 35(1) (1986)255-258.

[4]Week M, Zangs L, Computing the thermal behavior of machine tools using the finite element method-possibilities and limitations. Proceedings of the 16th MTDR Conference 16(1975)185-194.

[5]Xu ZZ, Liu XJ, Kim HK, Shin JH, Lyu SK, Thermal error forecast and performance evaluation for an air-cooling ball screw system. International Journal of Machine Tools and Manufacture, 51(7-8) (2011) 605-611.

[6]Ming X, Jiang S, A thermal model of a ball screw feed drive system for a machine tool, Proc. Inst. Mech. Eng. Part C: J. Mech. Eng. Sci. 225 (1) (2011)186-193.

[7]Li Z, Fan K, Yang J, Zhang Y, Time-varying positioning error modeling and compensation for ball screw systems based on simulation and experimental analysis [J]. The International Journal of Advanced Manufacturing Technology, 73 (2014) 5-8.

[8]Oyanguren A, Larrañaga J, I. Ulacia, Thermo-mechanical modelling of ball screw preload force variation in different working conditions. Int. J. Adv. Manuf. Technol., 2 (2018), pp. 1-17.

[9]Huang S, Feng P, Xu C, Ma Y, Ye J, Zhou K, Utilization of heat quantity to model thermal errors of machine tool spindle $[\mathrm{J}]$. The International Journal of Advanced Manufacturing Technology, 2018, 97(5_8):1733-1743.

[10]Li T, Zhao C, Zhang Y, Adaptive real-time model on thermal error of ball screw feed drive systems of CNC machine tools [J]. Springer London, 2017, 94(9-12):3853-3861.

[11]Yun WS, Kim SK, Cho DW, Thermal error analysis for a CNC lathe feed drive system. Int J Mach Tools Manuf 39(1999)1087- 1101.

[12]Ramesh R, Mannan MA, Po AN, Thermal error measure- ment and modeling in machine tools. Part I Influence of varying operation condition, Int J Mach Tools Manuf 43 (2003)391-40.

[13]Xu ZZ, Liu XJ, Thermal error forecast and performance evaluation for an air-cooling ball screw system. Int J Mach Tools Manuf 51(2011)605-611.

[14]Xu ZZ, Liu XJ, Study on thermal behavior analysis of nut/ shaft air cooling ball screw for high-precision feed drive. Int J Precis Eng Manuf 15(2014)123-128.

[15]Zhang Y, Yang JG, Jiang H, Machine tool thermal error modeling and prediction by grey Neural network. Int J Adv Manuf Technol 59(9-12) (2012)1065-1072.

[16]Lee J, Lee JH, Yang SH, Thermal error modeling of a horizontal machining center using fuzzy logic strategy. J Manuf Process 3(2) (2001)120-127.

[17]Ma C, Yang J, Mei XS, Zhao L, Dong HS, Zhang S, Dynamic Thermal-Structure Coupling Analysis and Experimental Study on Ball Screw Feed Drive System of Precision Machine Tools [J]. Applied Mechanics and Materials (2017)868:124-135.

[18]Han J, Wang LP, Wang HT, A new thermal error modeling method for NC machine tools. Int J Adv Manuf Technol 62(2012)205- 212.

[19]Wu CW, Tang CH, Chang CF, Shiao YS, Thermal error compensation method for machine center. Int J Adv Manuf Technol 59(2012)681-689.

[20]Wang W, Zhang Y, Yang JG, Zhang YS, Yuan F, Geometric and thermal error compensation for $\mathrm{CNC}$ milling machines based on Newton interpolation method. Proc 
IME C J Mech Eng Sci 227(2012)771-778.

[21]Wu H, Zhang HT, Guo QJ, Wang XH, Yang JG, Thermal error optimization modeling and real-time compensation on a CNC turning center. J Mater Process Tech 207 (2008)172-179.

[22]Xu ZZ, Choi C, Liang LJ, et al. Study on a novel thermal error compensation system for high-precision ball screw feed drive (1st report: model, calculation and simu- lation). Int J Precis Eng Man.16 (2015)2005-2011.

[23]Xu ZZ, Choi C, Liang LJ, et al. Study on a novel thermal error compensation system for high-precision ball screw feed drive (2nd report: experimental verification). Int J Precis Eng Man; 16(2015) 2139-2145.

[24]Zhang J, Li B, Zhou C, Zhao W, Positioning error prediction and compensation of ball screw feed drive system with different mounting conditions $[\mathrm{J}]$. Proceedings of the Institution of Mechanical Engineers, Part B: Journal of Engineering Manufacture, (2016)230(12).

[25]Wei X, Gao F, Li Y, Zhang D, Study on optimal independent variables for the thermal error model of CNC machine tools [J]. The International Journal of Advanced Manufacturing Technology, 98(2018) (1-4).

[26]Sun YP, Wang DL, Dong HM, et al. A seven-sensor con- figuration method for testing thermal error of a horizontal machining center with linear optical grating scale.

Proc IMechE, Part C: J Mechanical Engineering Science, 231(2016) 2681-2689.

[27]Li Y, Zhang J, Su D, Zhou C, Zhao W, Experiment-based thermal behavior research about the feed drive system with linear scale [J]. Advances in Mechanical Engineering, (2018)10(11): 168781401881235.

[28]Harris TA, Rolling Bearing Analysis, Wiley \& Sons, New York, 1991.

[29]Tian R, He R, Solution for heating of ball screw and environmental engineering, World Manuf. Eng. Mark. 3 (2004) 65-67.

[30]Verl A, Frey S, Correlation between feed velocity and preloading in ball screw drives, Ann. CIRP 59 (2) (2010) 429-432.

[31]Xu ZZ, Liu XJ, Kim HK, Shin JH, Lyu SK, Thermal error forecast and performance evaluation for an air-cooling ball screw system. Int J Mach Tools Manuf 51(2011)605-611.

[32]Xia J, Hu Y, Wu B, Shi T, Research on thermal dynamics characteristics and modeling approach of ball screw [J]. The International Journal of Advanced Manufacturing Technology, 43(2009) (5-6).

[33]Hu S, Ma C, Y J , Zhao L, Mei X, Gong G, Investigation into effect of thermal expansion on thermally induced error of ball screw feed drive system of precision machine tools. Int J Mach Tools Manuf 97(2015)60-17.

[34]Bapat VA, Srinivasan P, Method of Separation of Variables for the Solution of Certain Nonlinear Partial Differential Equations [J]. Journal of Basic Engineering, 1971, 93 (2):162.

[35]Zhang D, Jia H, Numerical Analysis of Leaky Modes in Two-Dimensional Photonic Crystal Waveguides Using Fourier Series Expansion Method with Perfectly Matched Layer[J]. 2007 E90_C (3):613-622.

[36]Yuan J, Yang J, N. Jun, Thermal error mode analysis and robust modeling for error compensation on a CNC turning center, Int. J. Mach. Tools Manuf. 39 (9) (1999) 1367-1381.

[37]Zhang LC, Zu L, A new method to calculate the friction coefficient of ball screws based on the thermal equilibrium [J]. Advances in Mechanical Engineering, 11(1) (2019) 168781401882073.

[38]Li R, Lin W, Zhang J, Chen Z, Li C, Shuang Q, Research on Thermal 
Deformation of Feed System for High-speed Vertical Machining Center [J]. Procedia Computer Science, 131(2018) 469-476. 
Figures

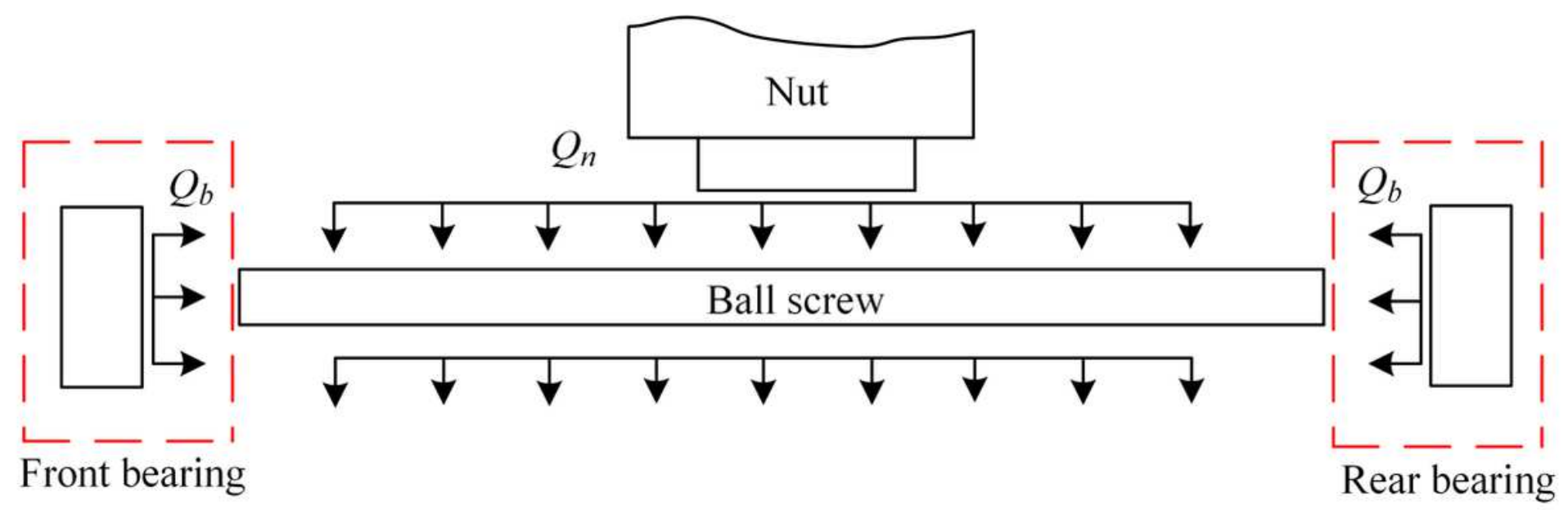

Figure 1

Schematic diagram of heat generation of ball screw feed system 


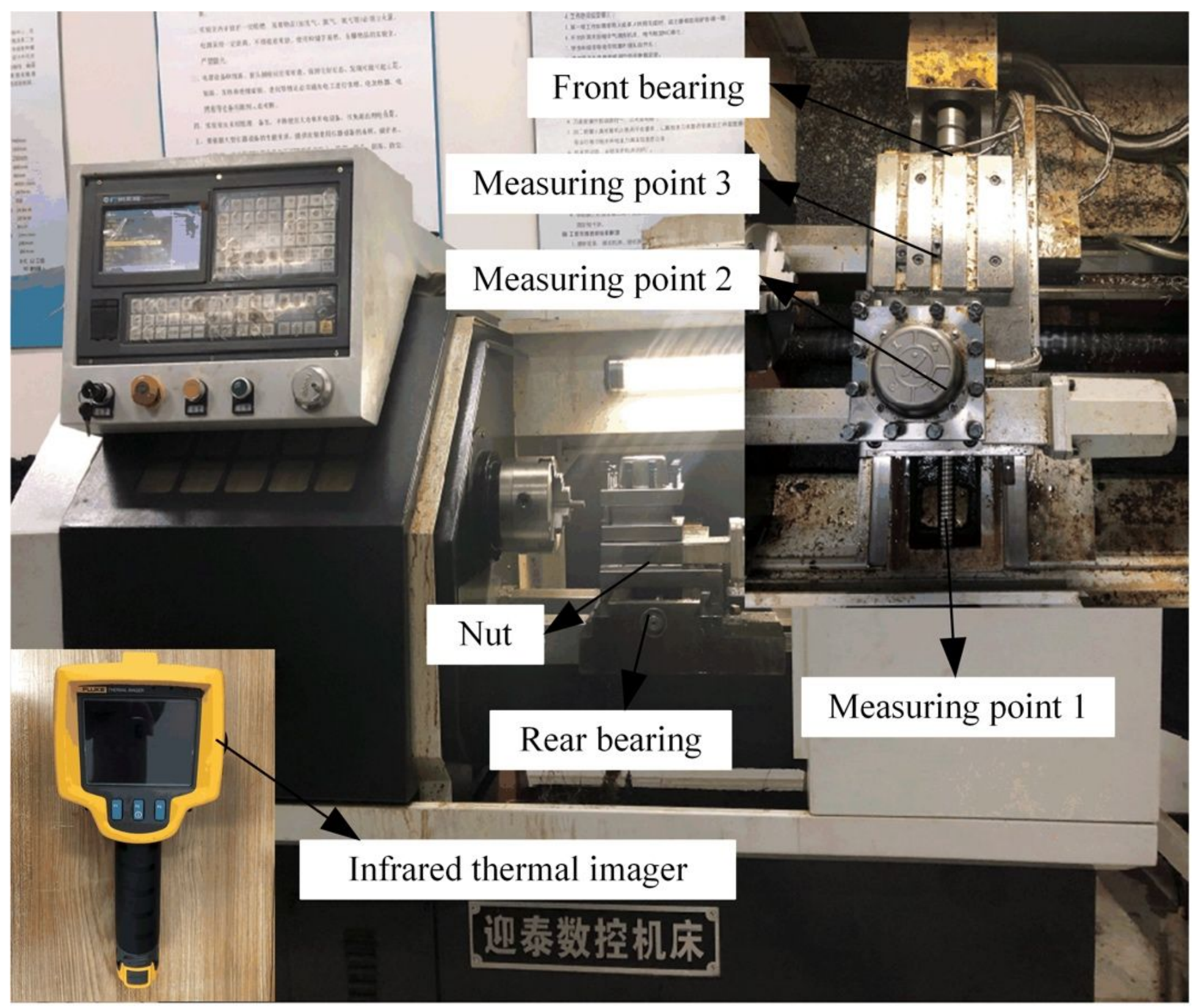

Figure 2

CNC machine tool fittings 


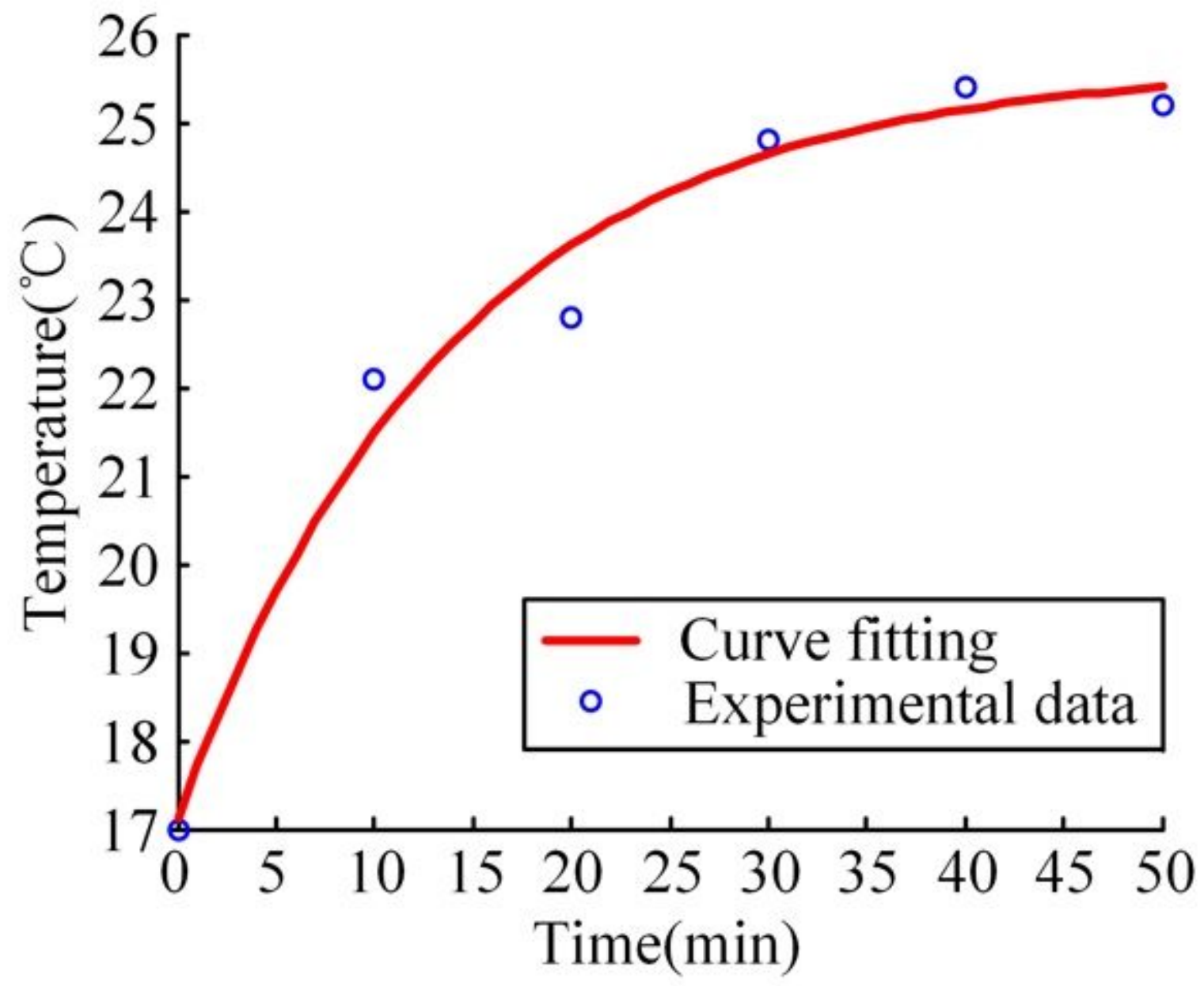

Figure 3

The change curve of the temperature of the front bearing with time 


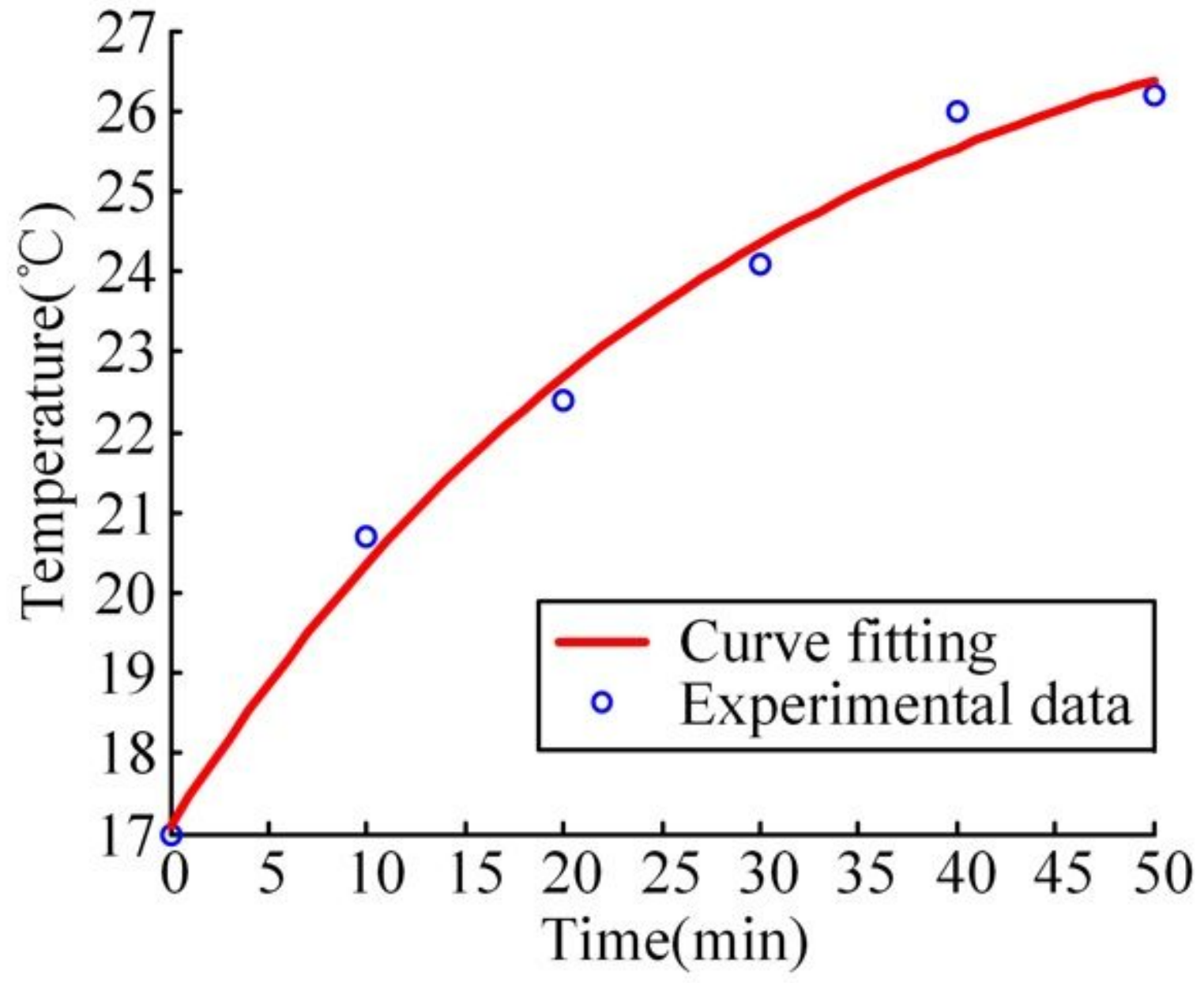

Figure 4

The change curve of the temperature of the rear bearing with time 


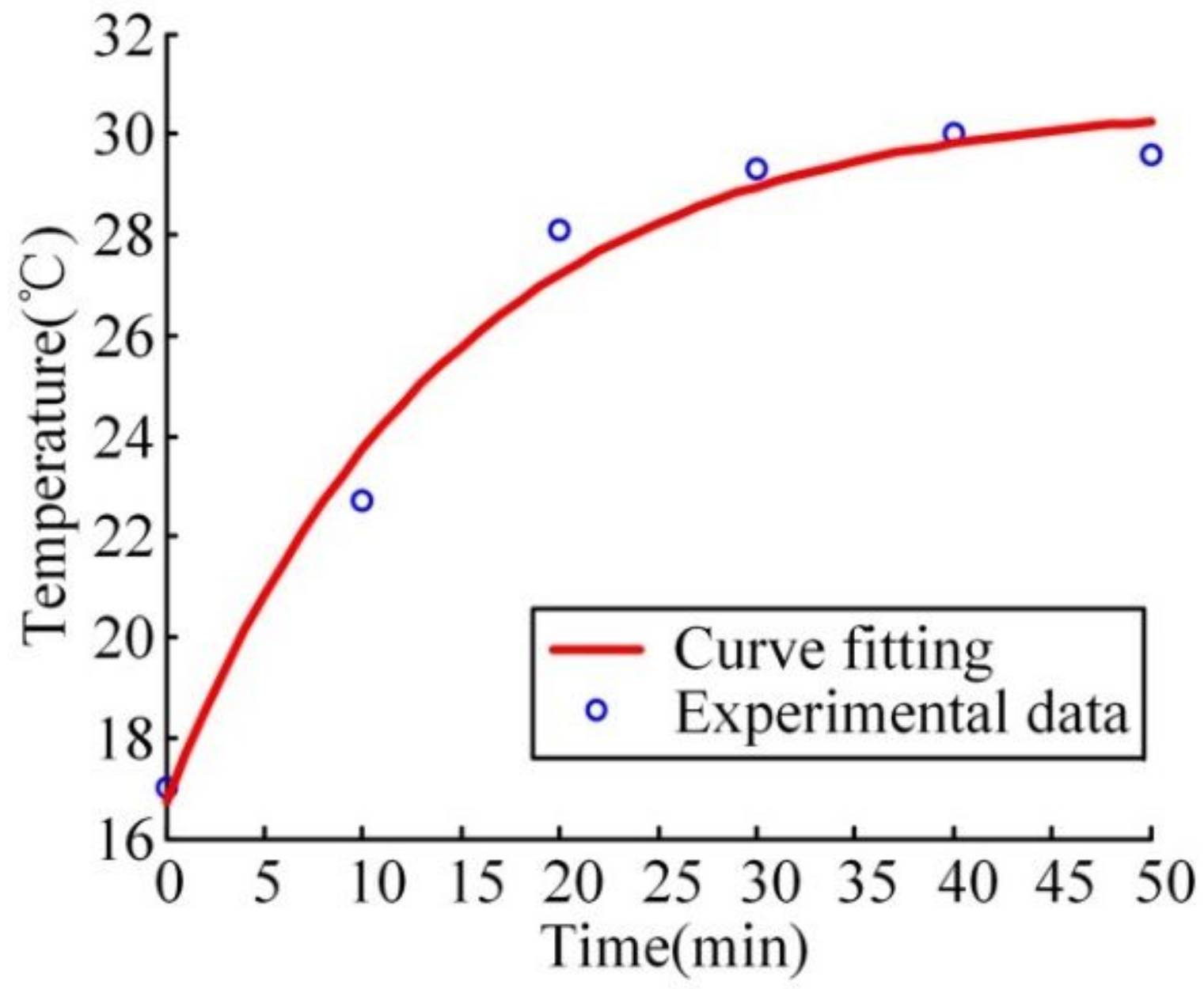

Figure 5

The change curve of the temperature of the nut with time 


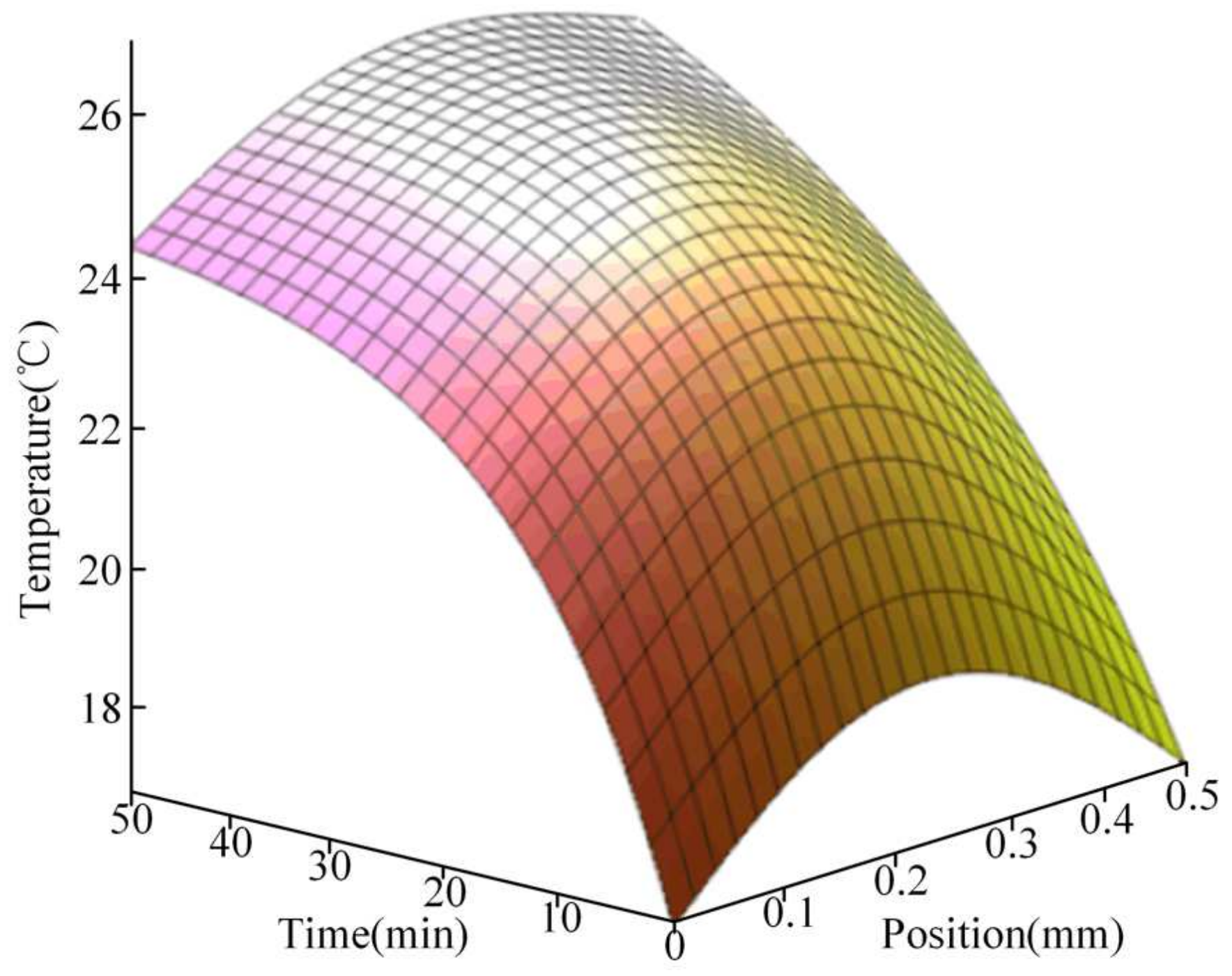

Figure 6

The change curve of the temperature of the ball screw with time and position

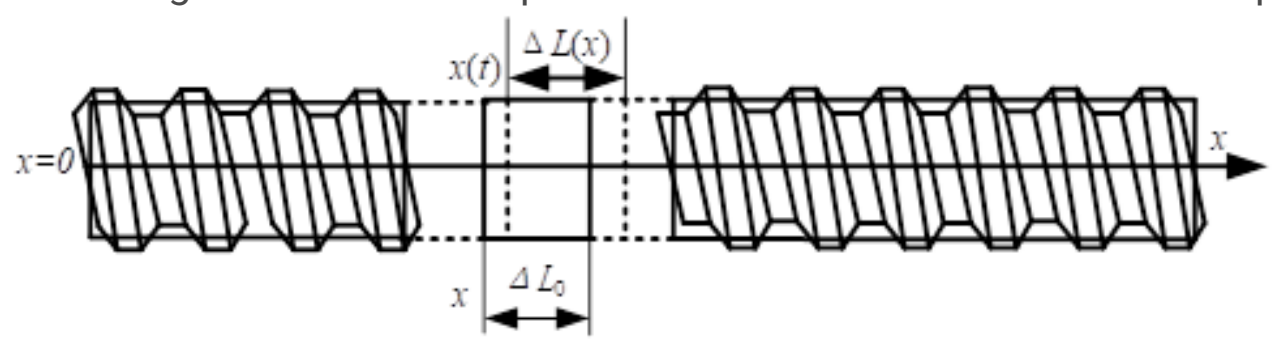

Figure 7

Schematic diagram of thermal expansion analysis of ball screw 


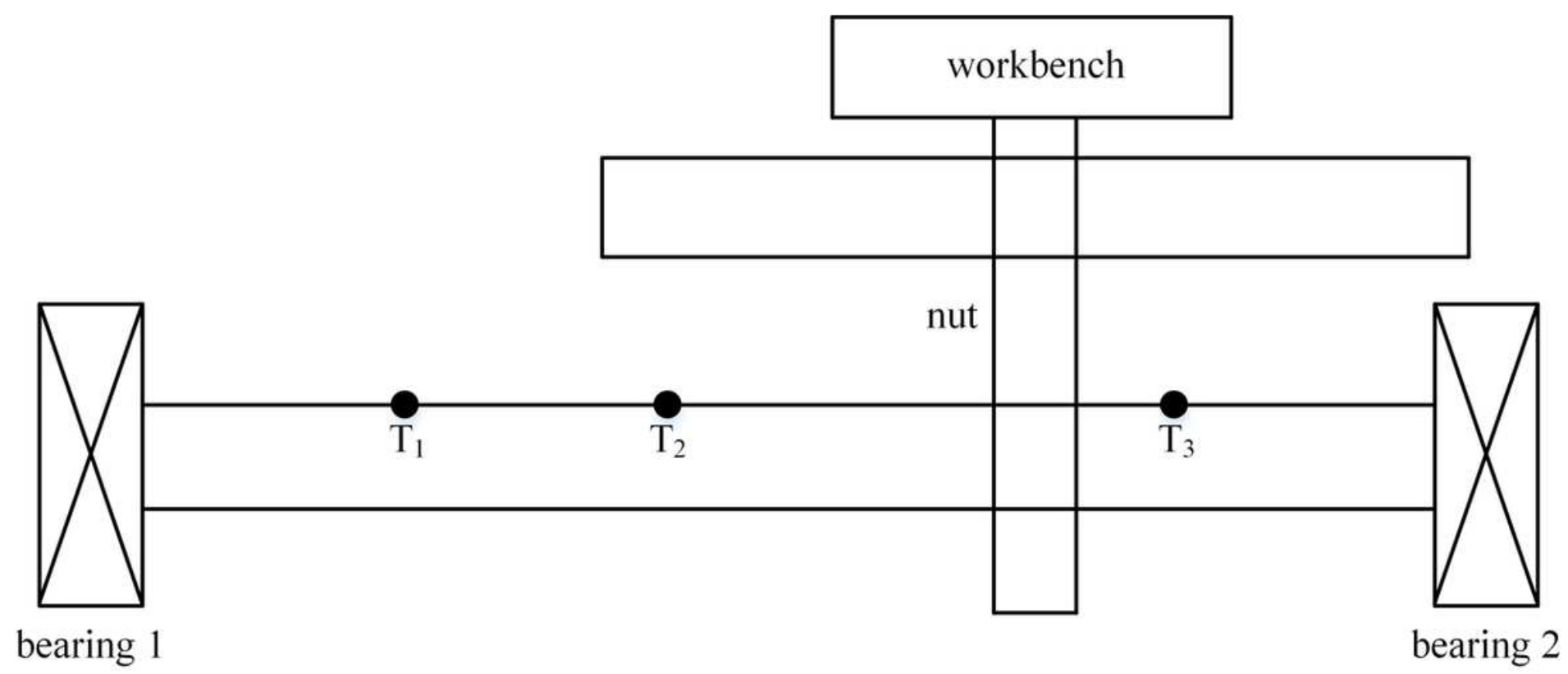

Figure 8

Distribution of measured points for the screw 


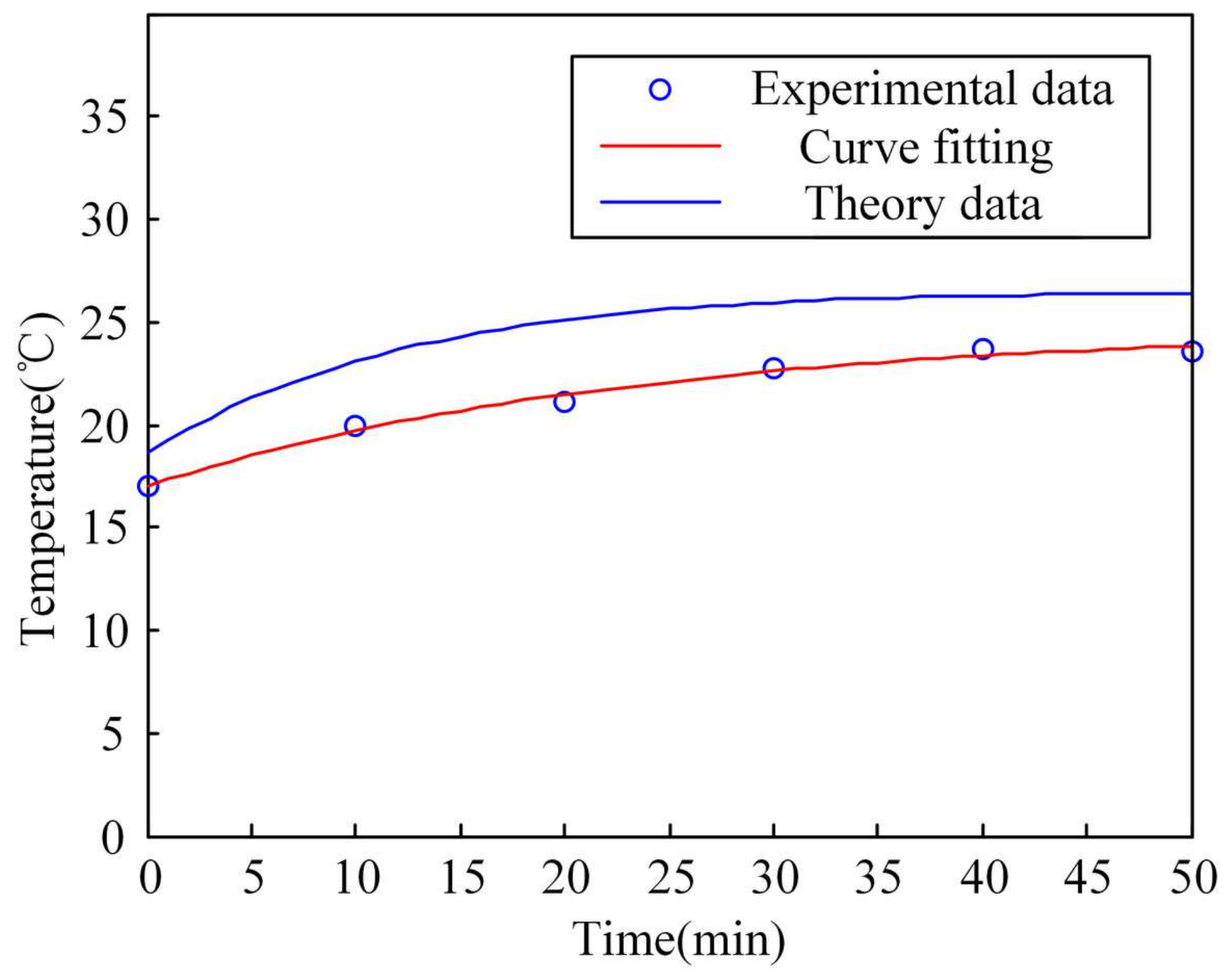

Figure 9

Comparison of test and theoretical temperature of ball screw at $100 \mathrm{~mm}$ 


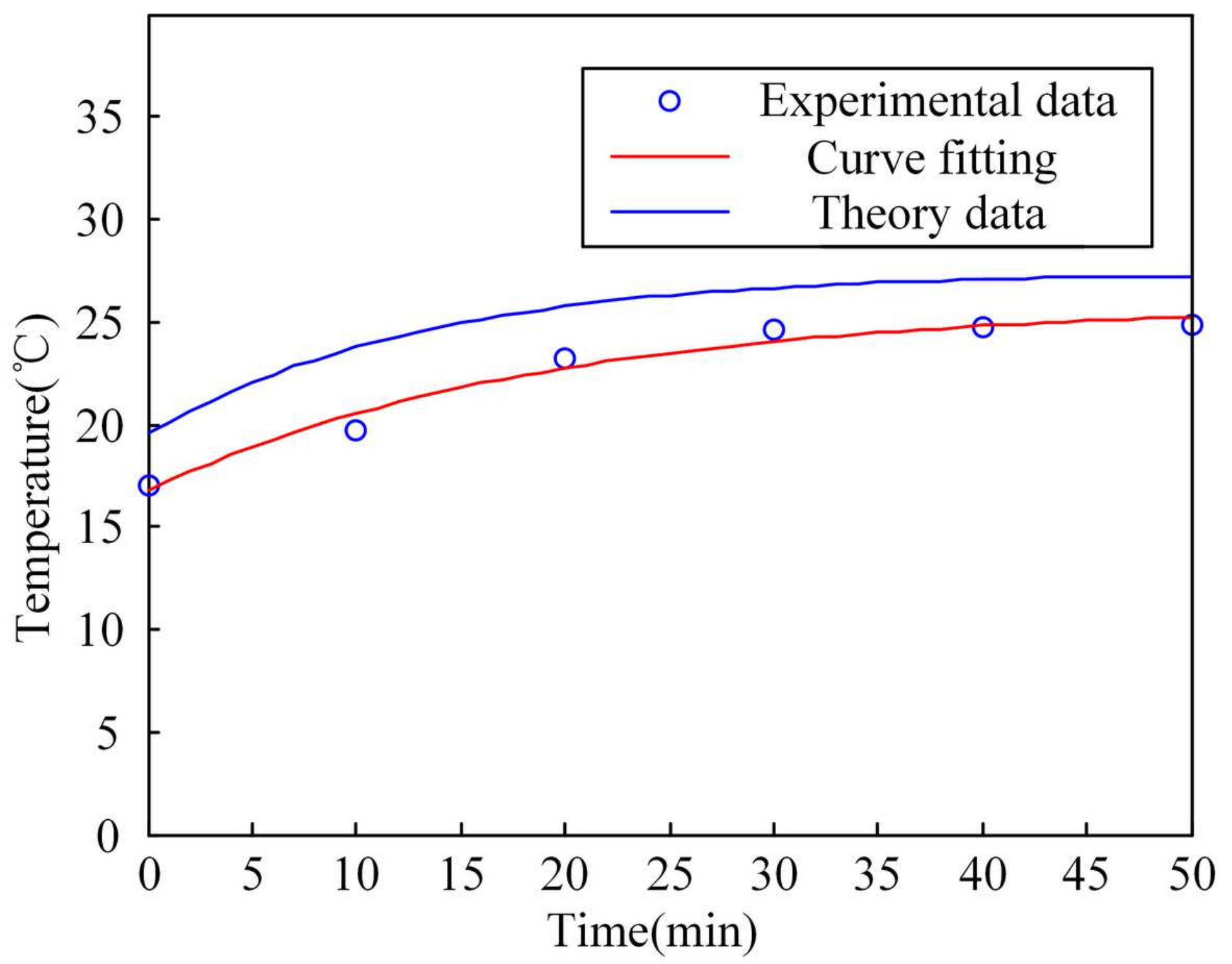

Figure 10

Comparison of test and theoretical temperature of ball screw at $200 \mathrm{~mm}$ 


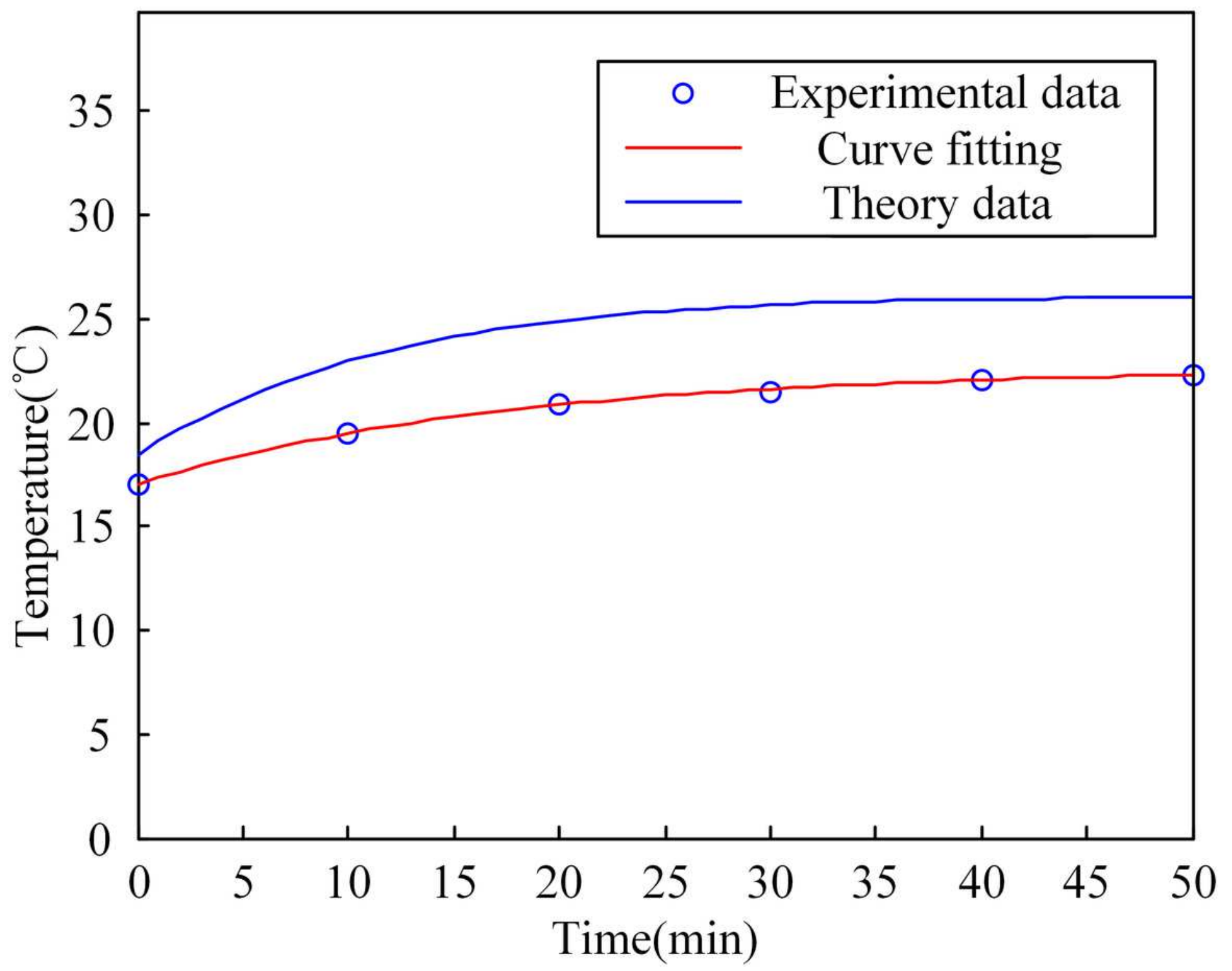

Figure 11

Comparison of test and theoretical temperature of ball screw at $400 \mathrm{~mm}$ 

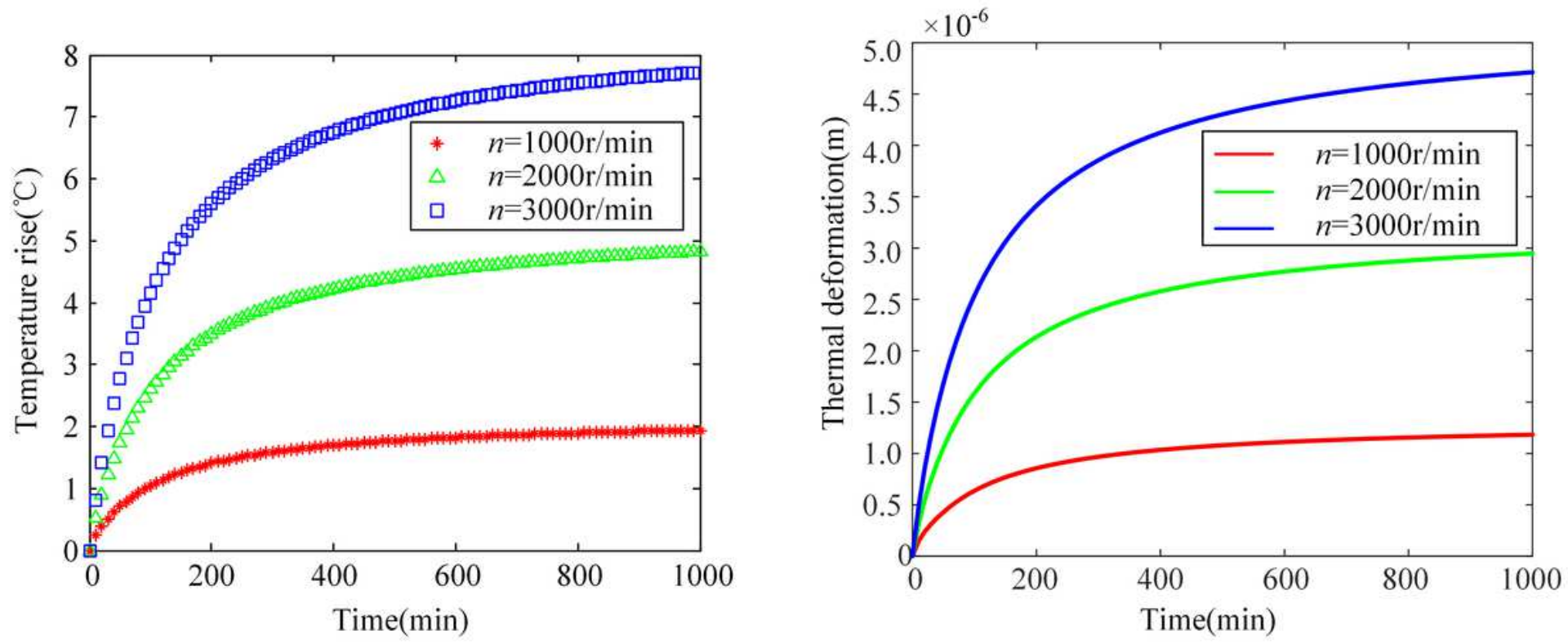

Figure 12

The temperature rising and thermal deformation of the lead screw changes with the speed
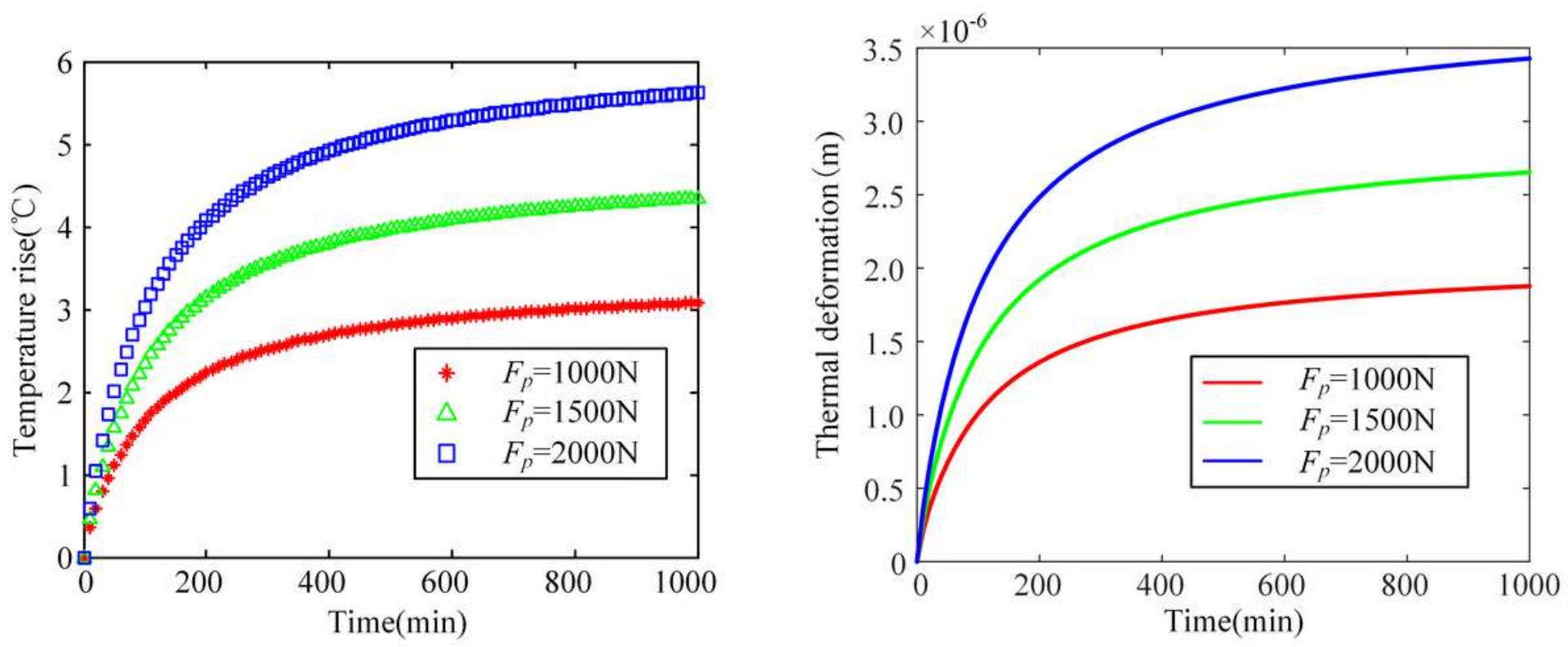

Figure 13

The temperature rising and thermal deformation of the lead screw changes with the preload 

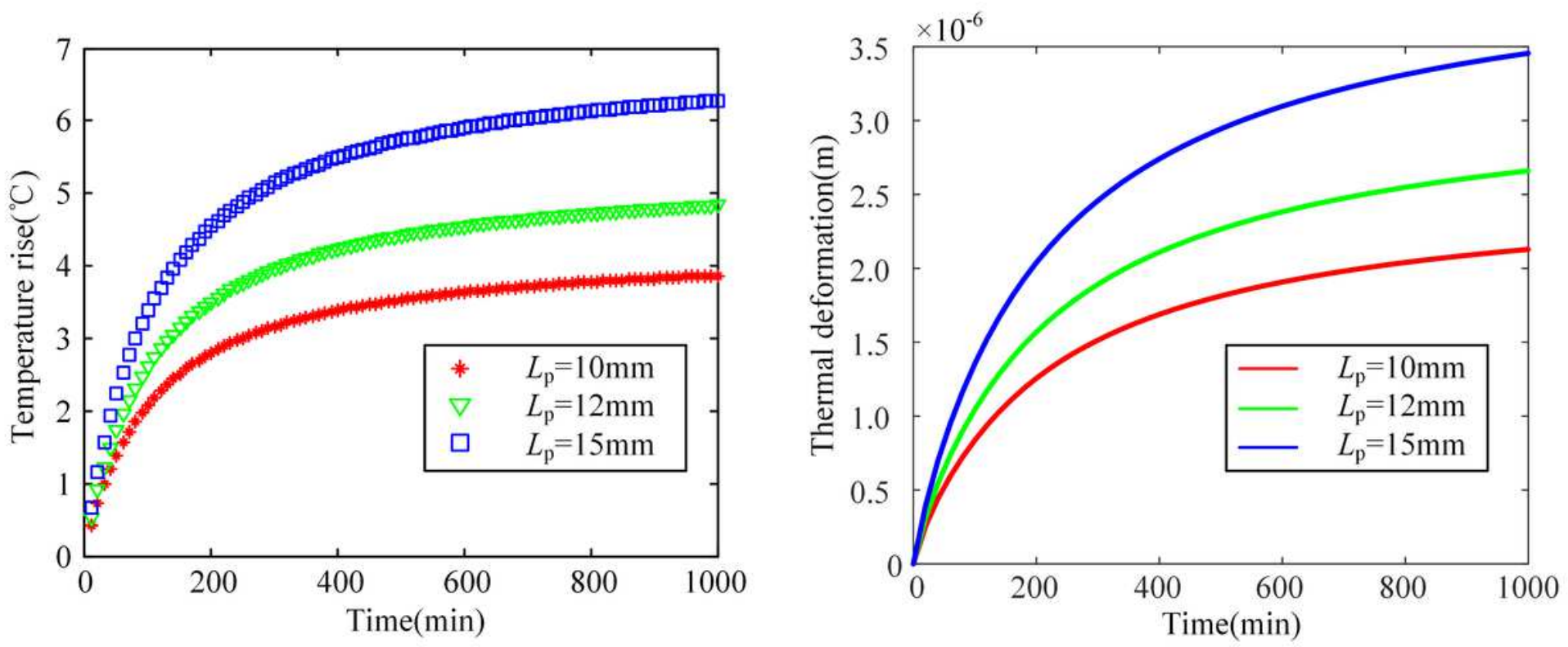

Figure 14

The temperature rising and thermal deformation of the lead screw changes with the lead
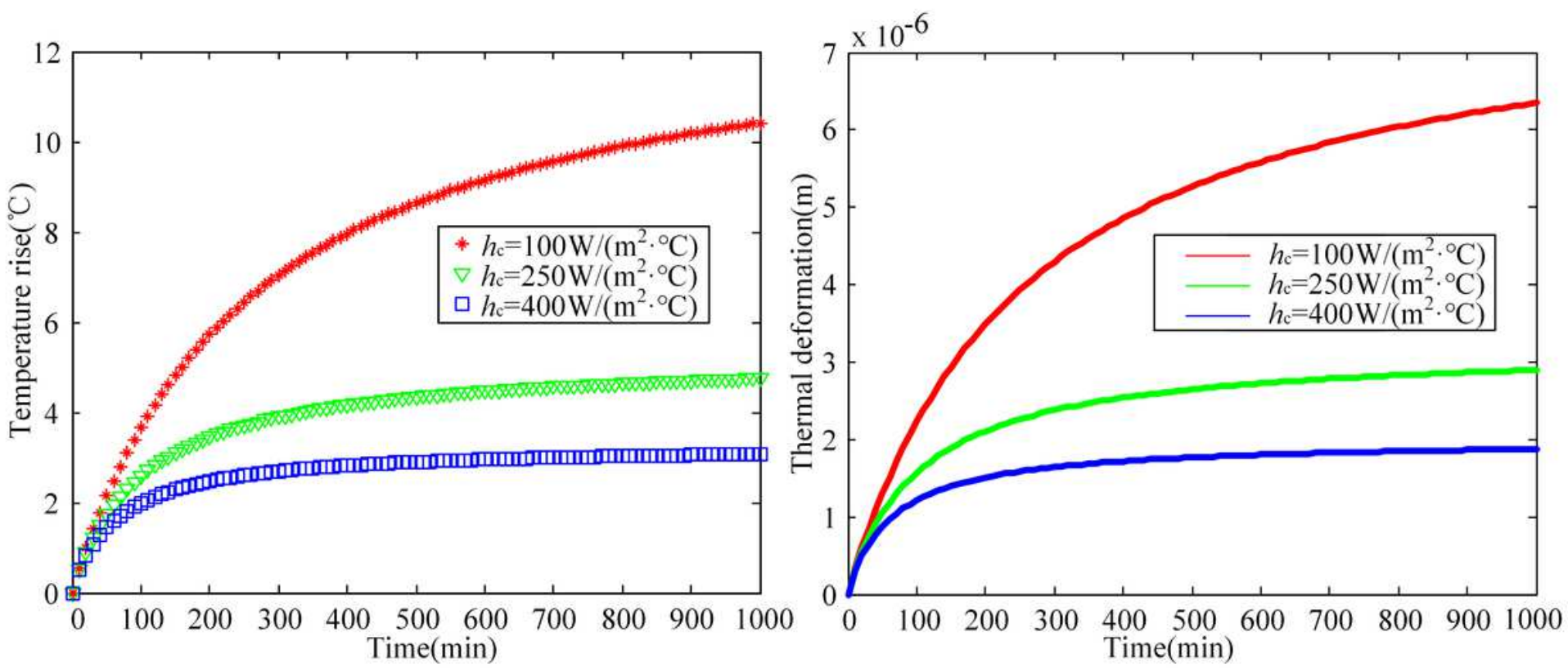

Figure 15

The temperature rising and thermal deformation of the lead screw changes with the lead 